\title{
An autoclave study of zirconium alloys with and without a hydride rim
}

J. Wei ${ }^{1}$, P. Frankel ${ }^{1}$, M. Blat ${ }^{2}$, A. Ambard ${ }^{2}$, R. J. Comstock ${ }^{3}$, Lars Hallstadius ${ }^{4}$, S. Lyon ${ }^{1}$, R.A. Cottis ${ }^{1}$ and Michael Preuss ${ }^{1}$

1: Materials Performance Centre, School of Materials, The University of Manchester, UK

2: EDF - R\&D, Moret sur Loing, France

3: Westinghouse Electric Co., Pittsburgh, USA

4: Westinghouse Electric Co., Sweden

\section{$\underline{\text { Abstract }}$}

Autoclave corrosion experiments were conducted on a number of zirconium alloys in different heat treatment conditions. The alloys tested in the present work were Zircaloy-4, ZIRLO ${ }^{{ }^{1}}$ and two variants of ZIRLO with significantly lower Sn levels, referred to here as $\mathrm{A}-0.6 \mathrm{~S} n$ and $\mathrm{A}-0.0 \mathrm{~S} n$. Typical corrosion kinetics with a change from pre- to post-initial transition was observed with ZIRLO and Zircaloy-4 displaying the shortest time to the initial transition after $120 \sim 140$ days of autoclave exposure, followed by $\mathrm{A}-0.6 \mathrm{Sn}$ materials after $140 \sim 260$ days. A-0.0Sn materials showed no sign of transition even after 360 days although one sample tested to 540 days had gone through transition. Material in the stress relieved condition (SR)

\footnotetext{
${ }^{1}$ ZIRLO $^{\circledR}$ is a registered trademark of Westinghouse Electric Company LLC in the United States and may be registered in other countries throughout the world. All rights reserved. Unauthorized use is strictly prohibited.
} 
generally experienced initial transition earlier than the same alloy in the recrystallised condition. Pre-transition samples had a universally black oxide layer, which eventually developed grey patches when transition occurred. Practically all non-hydrogen charged alloys showed a strong trend towards cubic oxide growth rates. Cathodic hydrogen charging was conducted to simulate end of life condition of cladding tubes, forming a hydride-rich rim region at the outer surface of the cladding tubes. Hydrogen charged materials generally experienced accelerated corrosion of different degrees with the exception of recrystallised A-0.0Sn and partially recrystallised A-0.6Sn showing no sign of acceleration. It therefore seems that increasing tin levels has a negative impact on autoclave corrosion behaviour for materials with and without a hydride-rich rim. In developing advanced alloys for use in cladding this effect has been balanced against the benefits that $\mathrm{Sn}$ is known to provide in-reactor, including robustness in corrosion behaviour and reduced irradiation growth. It was noted that most materials with a hydride-rich rim exhibit parabolic corrosion kinetics with decreased initial weight gain but increased overall weight gain.

\section{Introduction}

Zirconium based alloys has been the material of choice for fuel cladding, channels, spacer grids and guide tubes that comprise the structural components of fuel assemblies in water cooled nuclear power plants since the early 1950 s. The two physical properties of zirconium alloys, that largely influence their selection, are their excellent high-temperature water-corrosion resistance and very low thermal neutron absorption cross-section. The initial kinetics of zirconium alloy corrosion in 
high temperature pressurised water (i.e. prior to the initial transition) can be described by an approximately cubic growth rate law, rather than the parabolic law as predicated for diffusion controlled processes ${ }^{1-13}$. This is followed by successive cycles that involve a rapid increase in oxidation followed by a corrosion rate similar to the $1^{\text {st }}$ cycle. Note that the cyclic transitions are often approximated by a linear post-transition corrosion rate. These cyclic transitions are repeated until an accelerated, roughly linear, breakaway corrosion takes place ${ }^{3,} 5-8,11,14-19$. Considerable efforts have been made to understand the mechanisms behind such transition and breakaway since elimination or delay of such behaviour will greatly improve the overall corrosion performance of zirconium alloys. However, to date, our understanding of these two phenomena is still limited. A number of mechanisms have been proposed for the breakdown of the pre-transition oxide, and it has been suspected that more than one, if not all, of the mechanisms may be active in any given corrosion conditions ${ }^{5}$. Among them, one of the more prominent mechanisms involves the tetragonal to monoclinic phase transformation in the oxide due to a stress gradient inside the oxide film that might lead to cracking, as reported by Preuss et al. ${ }^{20}$ and various other researchers such as ${ }^{21,22}$. With a Pilling-Bedworth ratio of 1.56 from oxidation of zirconium to zirconia ${ }^{1,23}$ brings about a build-up of compressive stress inside the oxide layer with the highest stress level expected at the metal/oxide interface, decreasing towards the outer surface of the oxide. It has been suggested that these highly compressive stresses at the interface stabilises the tetragonal phase of the first oxide that forms at the interface $17,19,20,24-26$, as well as causing creep in the underlying metal substrate ${ }^{21}$. Subsequently, as the corrosion front progresses inwards, the stresses in the existing 
oxide relaxes, destabilising the tetragonal phase, which results in a martensitic phase transformation from tetragonal to monoclinic oxide associated with a further $5 \%$ volume expansion ${ }^{27}$. It is proposed that this additional significant volume expansion leads to cracking in the oxide that ultimately results in the cyclic corrosion kinetic transitions ${ }^{5,28,29}$.

During prolonged reactor service, zirconium cladding absorbs hydrogen generated during the corrosion reaction between water and zirconium, radiolysis of coolant water and in the case of PWR environment, the hydrogen overpressure ${ }^{30-32}$. Hydrides will be precipitated when the local hydrogen concentration reaches the solubility limit, which is $120 \mathrm{wt} . \mathrm{ppm}$ at $360^{\circ} \mathrm{C}{ }^{33,34}$. Given the temperature dependence of hydrogen solubility in zirconium ${ }^{35}$, preferential precipitation of hydrides occurs firstly at regions of lower temperature, which lay within the outer surface of fuel cladding at the metal/oxide interface. Such accumulation of hydrides has been correlated with breakaway corrosion once a high volume fraction of hydrides has been reached in the rim, although the underlying mechanism for this accelerated corrosion is still unclear. ${ }^{5,11,14,16,21,36-40}$. Microstructure observations of oxides grown on artificially formed hydride-rich rims have shown high levels of porosity $^{36,40}$. It has been suggested that the complex stress field at the metal/oxide interface will result in fracture of the brittle hydrides, disturbing the coherency at the metal/oxide interface and therefore reducing the integrity of the inner barrier oxide layer ${ }^{16}$. Alternatively, because the volume expansion during hydride formation $\left(17 \%{ }^{41-43}\right.$ ) reduces the overall Pilling-Bedworth ratio to 1.3 (i.e. for the oxidation of zirconium hydride), it has been suggested that this could result in lower 
compressive stresses in the oxide ${ }^{44}$. Previous work has shown that a reduction of tin content delays the transition to breakaway corrosion in $\mathrm{Zr}-\mathrm{Sn}-\mathrm{Nb}-\mathrm{FeCrV}$ alloys ${ }^{45}$ and it is difficult to see how the two arguments above can be affected by alloy chemistry. Note that alloy chemistry may indirectly impact breakaway by controlling hydrogen pickup and the propensity for hydride rim formation.

It should also be noted that $\mathrm{Sn}$ is well known to have both positive and negative impacts on the in-reactor corrosion rate and growth acceleration at high burnups of PWR cladding. A reduction of the tin content generally improves the corrosion resistance, e.g., for Zircaloy- $4{ }^{46}$ and advanced alloys like Westinghouse ZIRLO ${ }^{{ }^{*}} 47$, 48. This insight has been utilized over the years to improve cladding alloys by reducing tin. However, tin is also known to provide a robustness and predictability of the corrosion behaviour, e.g., it protects against enhanced corrosion in high lithium and abnormal chemistry conditions ${ }^{49}$. Tin addition also reduces the corrosion enhancement of weld regions compared to the non-weld region, and reduces the irradiation growth acceleration of zirconium alloys at high burnups believed to be due to hydrogen ${ }^{50}$. These contradictory effects of tin have been balanced in the latest generation of advanced alloys, e.g., Westinghouse Optimized ZIRLO ${ }^{\mathrm{TM} 2}$.

The purpose of the present paper is to provide detailed experimental data recorded during extensive autoclave corrosion testing in simulated primary water chemistry of 3 different $\mathrm{Zr}$-Nb-Sn alloys with varying Sn content, and two Zircaloy-4 variants (Nb-free $\mathrm{Zr}$ alloy). In some cases, material was available as clad tubes while in other cases it was available as sheet. A further variable was the final heat treatment of the material either producing a stress relieved, partially recrystallised or fully

\footnotetext{
${ }^{2}$ Optimized ZIRLO ${ }^{\text {TM }}$ is a trademark of Westinghouse Electric Company LLC in the United Sates and may be registered in other countries throughout the world. All rights reserved. Unauthorized use is strictly prohibited.
} 
recrystallised condition. While these experiments focused on early corrosion kinetics and time to the initial transition, tube material was also cathodically hydrogen charged prior to autoclave testing in an attempt to simulate end-of-life condition of irradiated reactor claddings in order to identify material sensitivity to breakaway corrosion.

\section{Experimental}

\section{Materials Preparation}

Two types of sample geometry were involved in this study. Tube samples were 30 $\mathrm{mm}$ long and $9.5 \mathrm{~mm}$ in diameter while sheet samples were $30 \times 20 \mathrm{~mm}^{2}$. Note that the rolling direction for sheet samples was oriented parallel to the longer side. The wall thickness of all tube material is $0.6 \mathrm{~mm}$, while the thickness of the sheet samples is $0.5 \mathrm{~mm}$ for ZIRLO material, $0.7 \mathrm{~mm}$ for Zircaloy-4 (A) and $5.0 \mathrm{~mm}$ for Zircaloy-4 (B). All samples were pickled in a solution of 10 vol.\% hydrofluoric acid, 45 vol.\% nitric acid and 45 vol.\% distilled water for 3 minutes, removing less than $0.02 \mathrm{~mm}$ thick of material from the sample surface. Chemical composition and asreceived hydrogen concentration of each material were determined at the EDF Research and Development facility in Moret-Sur-Loing, France and these are presented in Table 1 . The alloys were provided in either two or three heat treatment conditions: stress relieve annealed (SR), partially recrystallised ( $p R X$, only for A-0.6Sn) and recrystallised (RX). Westinghouse provided all material apart from the $5 \mathrm{~mm}$ thick Zircaloy-4 (B) sheet, which was provided by Rolls-Royce plc. The rationale behind the choice of alloys was to compare a Nb containing alloy (ZIRLO sheet) with a non-Nb containing alloy (Zircaloy-4 sheet) and to study the effect of 
$\mathrm{Sn}$ in Nb containing alloys (tin content decreases from ZIRLO to A-0.6Sn to A-0.0Sn). Note that $\mathrm{A}-0.0 \mathrm{~S} n$ is an experimental alloy while all other alloys are commercial alloys.

\section{Cathodic hydrogen charging}

Cathodic hydrogen charging was conducted on pickled tube samples in a $0.1 \mathrm{~mole} / \mathrm{L}$ $\mathrm{KOH}$ solution with a fixed current density of $10 \mathrm{~mA} \mathrm{~cm}{ }^{-2}$. This process resulted in the formation of a hydride-rich rim with fairly consistent thickness on the outer surfaces of tube samples. The 10 -day charging process was followed by a 24 -hour homogenisation heat treatment at $400^{\circ} \mathrm{C}$ in $\mathrm{Ar}$ to redistribute some of the hydrogen further into the bulk of the test piece. Averaged hydrogen levels of individual test pieces were determined by inert gas fusion analysis using a H-MAT 2500 (Ströhlein) analyser. This method only accounts for overall hydrogen concentration and provides no information regarding the distribution of hydrogen. Using a Philips $\mathrm{X}^{\prime}$ Pert MPD operating at $45 \mathrm{kV}$ (Cu-tube) in glancing-angle set up $\left(\theta=6^{\circ}\right)$, it was revealed that samples with an overall hydrogen level between 600 to $700 \mathrm{wt} . \mathrm{ppm}$ have the top few microns of material composed of around $60 \%$ of $\delta$-hydride ${ }^{51}$. This corresponds to an average hydrogen content in the rim of about $11,000 \mathrm{wt} . \mathrm{ppm}$. In comparison, it has been predicted that a solid hydride rim would form once the oxide had grown to a thickness of $60 \mu \mathrm{m}$. These predictions have also been confirmed by hot cell observations ${ }^{52}$. Note that a fixed incident beam at $\theta=6^{\circ}$ ensures $90 \%$ of the signal is collected from the top $3 \mu \mathrm{m}$ of the specimen surface. Since the duration of the autoclave corrosion experiments of the hydrogen charged samples was relatively short, only material from within this range was consumed. 
More details regarding the cathodic charging procedure and the microstructure analysis of the hydride rim can be found in ${ }^{51}$.

\section{Autoclave corrosion}

Corrosion experiments were conducted in static isothermal autoclaves operating at $360^{\circ} \mathrm{C}$ in simulated primary water chemistry ( $\mathrm{Li}$ and $\mathrm{B}$ were added in the form of lithium hydroxide and boric acid, $\mathrm{Li}=2$ wt.ppm, $\mathrm{B}=1000$ wt.ppm), at a saturation pressure of around $18 \mathrm{MPa}\left(360^{\circ} \mathrm{C}\right)$. The autoclave was deaerated each time during heat up at $125^{\circ} \mathrm{C}$. The tests were performed consistent with ASTM G2 standard. To enable tracking of oxidation weight gain as a function of autoclave corrosion exposure, as well as generating samples that have experienced different duration of autoclave exposures, sets of 4 samples were introduced into the autoclave periodically (every 20 days in the case of non-hydrided samples, every 10 days in the case of hydrided samples). Samples were rinsed in de-ionized water, dehydrated with ethanol and compressed air and weighed prior to loading into a stainless steel basket and insertion into the autoclave, Figure 1. A graphical representation of the detailed loading plan as well as an autoclave test scheme is presented in Figure 2, highlighting the insertion time of each set, and the spread of individual samples from each set across different layers of the basket. The positions of individual samples were not altered throughout the autoclave corrosion tests. The loading plan was introduced as a measure to counter any possible temperature heterogeneity inside the autoclave. However, in most cases no significant differences in corrosion kinetics were observed for samples in the same condition. Periodic weighing of the exposed samples was conducted between individual 
exposures, after which the samples were re-installed to their original position inside the autoclave. Both pre- and post-corrosion weight measurements were conducted on a METTLER TOLEDO XS205 DualRange Analytical Balance (repeatability $0.01 \mathrm{mg}$, sensitivity accuracy $\left.4 \times 10^{-6} \cdot R n t\right)$. The balance was re-calibrated after every 10 measurements. Note that weight measurements were normally conducted within hours after opening the autoclave. Samples were dipped into ethanol and dried by compressed air before conducting the weight measurements.

The corrosion exposures on non-hydrided (reference) materials aimed to provide samples and corrosion kinetic data from the early stage of corrosion up to and just exceeding the $1^{\text {st }}$ transition, while exposures on hydrided materials aimed to provide similar data but including breakaway behaviour. The non-hydrided and hydrided samples were exposed in two separate autoclaves.

\section{$\underline{\text { Result and Discussion }}$}

\section{Corrosion kinetics of non-hydrided reference material}

Figures 3 summarises the averaged pre-transition corrosion weight gain plotted as a function of autoclave exposure time for all 12 non-hydrided materials. The pretransition corrosion kinetics can be described by

$$
\Delta W=K_{p} t^{n}
$$

where $\Delta W$ is the sample weight gain in units of $\mathrm{mg} / \mathrm{dm}^{2}, t$ is the autoclave exposure time in days, $n$ is the corrosion kinetics exponent and $K_{p}$ is the rate constant which is a function of temperature $\left(360^{\circ} \mathrm{C}\right.$ in this study) and alloy chemistry. Linear regression analysis was applied to extract the kinetic parameters 
from the data, and the fitted values can be found in Table 2 together with the required exposure time and weight gain to reach first transition. Each fit was based on corrosion data repetitively collected on 20 individual samples. The data show that the corrosion kinetics tend to follow a cubic rather than a parabolic law, which has been often reported by other researchers (for instance ${ }^{5}$ ). No correlations between exponent, $K_{p}$ values or time to first transition were identified. Neither was it possible to find any correlations between $n$ and alloy chemistry. However, most alloys in the stress relieved condition showed slightly more cubic growth kinetics as well as greater $K_{p}$ values than the equivalent alloy in the recrystallised condition.

Weight gain curves of for example alloys from each condition are shown in Figure 4 to 9. Note that weight gain data for an individual measurement, instead for averaged ones, are plotted in Figure 4 to 9 , illustrating the level of scatter. Photographs of actual samples are also included displaying the surface features of the pre-/post-transition oxide. A more detailed example of the change of oxide surface appearance before, during and after transition is given for sheet ZIRLO - SR in Figure 10. It is clear that the onset of transition was accompanied by the appearance of small grey spots on the black oxide surface. The grey spots then grew bigger, spread across the surface and eventually formed a uniform layer of grey oxide covering the entire surface of the sample. Note that Figure 10 (g) was taken on a specimen with a further 440 days of exposure after reaching transition. Since sheet ZIRLO - SR material reached its transition in 100 days, the sample shown in Figure $10(\mathrm{~g})$ is expected to have experienced at least 5 transitions. The 
oxide appearance at this stage was significantly lighter than that observed 40 days after the first transition.

With up to 300 days of autoclave exposure recorded, non-hydrided A-0.0Sn materials showed identical kinetics in both SR and RX conditions as demonstrated in Figure 4. No trace of a transition was observed and a black oxide was seen as early as after 20 days of corrosion and for all samples to 300 days of corrosion, Figure 4 (A), (C) and (D). A second batch of autoclave exposures, aimed at recording long term corrosion kinetics, was conducted on A-0.0Sn material. These tests confirmed that $\mathrm{A}-0.0 \mathrm{Sn}$ showed no sign of a transition up to 360 days of exposure and $\sim 45$ $\mathrm{mg} / \mathrm{dm}^{2}$ weight gain, but a dark and light patchy surface (Figure $4(B)$ and $(E)$ ) after 540 days of exposure and $\sim 80 \mathrm{mg} / \mathrm{dm}^{2}$ weight gain. It is hence suggested that A0.0Sn materials (both SR and RX conditions) will initiate transition between 360 540 days of exposure. Weight gain data collected during the second batch of autoclave exposures is not included since only 2 data points exist.

Similar pre-transition corrosion kinetics was recorded for non-hydrided A-0.6Sn (Figure 5). During transition, all samples displayed the expected patchy oxide surface of black and grey areas (Figure 5 (B), (D) and (F)). The longest time to transition was achieved by the partially recrystallised material ( $p R X)$ after around 260 days of exposure. At this stage, the increase in corrosion rate was however only very modest. Pre- to post-transition was observed after 200 days of exposure in A0.6Sn SR material with again only a modest increase in corrosion kinetics. In contrast, A-0.6Sn in the recrystallised condition displayed a far more dramatic acceleration in corrosion around 200 days of exposure. However, indications of 
transition were detectable from the change of surface oxide appearance from around 140 days of exposure. The corrosion data also suggest (Figure 5) that the recrystallised material undergoes a long transition regime of approximately 100 days. Figure 6 sheds more light onto this behaviour by presenting the corrosion data from two different sets. The 4 individual samples within each set were installed at different heights of the autoclave basket (Figure 2) but displayed almost no variation in corrosion kinetics. However, there is a distinguishable difference in terms of set 1 and 3 (i.e. sets that were put into the autoclave at a different time, see Figure 2). Such variation is not observed in any other alloy or heat treatment condition. The root cause of such variation is currently not clear.

Of all the materials tested, transition occurred earliest on ZIRLO with the transition for tube material in the stress relieved (SR) and recrystallised (RX) conditions reached after 120 days and 140 days respectively (Figure 7). Similarly, sheet ZIRLO SR material reached transition in 100 days while RX material reached transition in 120 days (Figure 8 ).

Corrosion kinetics for sheet Zircaloy-4 were similar to those for ZIRLO in terms of time to transition and the earlier occurrence for stress relieved material, Figure 9. However a noticeably earlier transition was observed for the thicker of the RX materials, Zircaloy-4 (B), than for the thinner Zircaloy-4 (A). The pre-transition corrosion rate also appeared to be lower for the recrystallised material compared to the stress relieved condition.

The data obtained for Zircaloy-4 and ZIRLO seem to point to a general trend for earlier transition in stress relieved materials, however the opposite is seen for A- 
$0.6 \mathrm{Sn}$. In the case of A-0.0Sn, no distinction between the two conditions can be made as the material did not undergo transition in the time frame of detailed corrosion studies. No significant difference in corrosion kinetics during autoclave testing was observed between ZIRLO (sheet or tube) and Zircaloy-4 sheet. In contrast, a clear trend was found when comparing ZIRLO, A-0.6Sn and A-0.0Sn with very significant delays in the onset of transition as the tin content in the alloy is reduced. Other researchers have reported previously a similar effect of Sn ${ }^{53-57}$ for Zircaloys (not containing $\mathrm{Nb}$ ), an experimental $\mathrm{Zr}$-Sn-0.19Fe-0.10Cr alloy (not containing $\mathrm{Nb}$ ) and $\mathrm{Zr}-\mathrm{Nb}$ binary alloys with $0.1-1.0 \mathrm{wt} . \% \mathrm{Nb}$ content. Usually, the differences in corrosion performance have been attributed to effect that tin has on the amount of tetragonal phase near the metal/oxide interface. Although some authors have suggested that increased tin levels in Zircaloys destabilises tetragonal zirconia ${ }^{57}$, there is substantial evidence that tin is in fact a tetragonal phase stabilising element ${ }^{53,54,58,59}$.

\section{Corrosion kinetics of hydrided material}

Corrosion weight gains of both non-hydrided reference and hydrided alloys are plotted in Figure 11 to 17 against exposure time. Photos of each hydrided alloy after 40 days of exposure are inserted demonstrating the surface appearance of the oxide at this stage. After 80 days of autoclave exposure, all hydrided alloys showed evidence of faster corrosion kinetics than the non-hydrided reference samples apart from recrystallised A-0.0Sn and partially recrystallised A-0.6Sn. The weight gain values after 80 days are compared to those recorded for non-hydrided samples in Table 3. Apart from the two conditions that did not show any accelerated 
corrosion at 80 days, material with a hydride rim showed $30-60 \%$ increased weight gain compared to the reference non-hydrided conditions. It was also noticeable that samples that showed accelerated corrosion generally displayed a white oxide colour with small regions of black oxide, while alloys that showed no accelerated weight gain displayed a more uniform black oxide similar to their reference conditions. A-0.6Sn - RX experienced a moderate degree of acceleration and showed a grey oxide appearance. The exception is hydrided ZIRLO - SR, which displayed the highest weight gain and greatest acceleration while the oxide surface was characterised by approximately equal amounts of black and white oxide present in patches (Figure 16). It was also noticed that compared to the reference samples without a hydride rim, some hydrided alloy conditions showed relatively little oxide weight gain during the first 5 days, with a subsequent increase in their corrosion rate from 5 to 10 days .

The corrosion kineticsexponent $n$, rate constants $K_{p}$ and $R^{2}$ fitted to the data for each alloy condition are presented in Table 3. In contrast to the non-hydrided reference material, the corrosion rates for most hydrided alloys follow a parabolic law. No correlations were established between $n$ or $K_{p}$ and alloy chemistry or heat treatment conditions. A parabolic rate law is expected for a corrosion process controlled by either the bulk ${ }^{7}$ or by grain boundary diffusion through a thickening barrier layer, which is more rapid than bulk diffusion and expected to take predominant role ${ }^{60,61}$. It has been argued that the near cubic kinetics of reference material arise from the reduction of grain boundary area as the oxide thickens, i.e. due to preferential growth of oxide grains ${ }^{5}$. This argument is supported by many 
studies on the evolution of oxide grain structure where columnar oxide grain is widely observed ${ }^{62-67}$. As mentioned earlier, in most cases material with a hydride rim showed relatively slow early oxide growth. Figure 18 plots the rate constant $K_{p}$ as a function of the kinetic exponent $n$. It is interesting to note that there is a relationship between the two and that in fact the oxide seems to become more protective ( $n$ is smaller) when the diffusion rate of ionic species seems to be faster (larger $K_{p}$ ), bear in mind that the regression analysis process will produce $K_{p}$ and $n$ values that are correlated. This is true when comparing between reference and hydrided material but also when comparing within each class of material. This behaviour confirms the differences in the oxidation mechanism between zirconium hydride and zirconium metal, with zirconium hydride showing close to classical diffusion-controlled (parabolic behaviour). It also suggests that ionic species transport through the oxide is not the rate limiting step when the oxide has grown to a certain thickness.

The observed corrosion acceleration and the general tendency of parabolic towards linear law oxide growth in hydrided material are difficult to explain in view that not all alloys show the same behaviour. Three possible explanations are suggested to account for the differences observed:

- Since the Pilling-Bedworth ratio is lower, lower compressive stress is expected for oxide grown on hydrided samples ${ }^{44}$, making inward diffusion of oxygen easier ${ }^{68}$ as pores on grain oxide grain boundaries ${ }^{69}$ might form a network for fast diffusion. 
- Oxide formed on hydrided material maintains a relatively uniform thickness and morphology as oxide thickens, providing a relatively constant grain boundary area for oxygen transport, i.e. the diffusion paths have constant tortuosity compared with the oxide formed on zirconium metal ${ }^{66}$.

- Transformation from tetragonal to monoclinic oxide happens earlier in hydrided material due to lower compressive stress at the oxide/hydride interface. The subsequent formation of cracks ${ }^{28,29}$ might enhance the transport of corrosion species to the metal-hydride/oxide interface, which would be expected to reduce the protective nature of the oxide with potential parabolic or even linear rate of corrosion.

Further investigations such as electron microscopy are required before the last two explanations can be confirmed or rejected. It is possible that more than one route will be active in any given case.

In-pile corrosion performance of zirconium fuel cladding is dependent on the type of reactor, burnup, coolant chemistry, in-pile location, etc and should generally be treated on a case by case basis. The progression of corrosion in such case is generally presented as a function of burnup rather than exposure time. Earlier studies concentrating on Zircaloys showed that corrosion acceleration could occur at high burn up over the range of $35-93 \mathrm{GWd} / \mathrm{tU}$, corresponding to an acceleration factor of 1.5-3 in PWRs (the acceleration factor for in-reactor performance is extrapolated from weight gain of samples with and without breakaway) ${ }^{14,}$,0-81. Similar acceleration was also observed in Nb containing alloys such as $M 5^{{ }^{3}} 14,71$,

\footnotetext{
${ }^{3} \mathrm{M} 5^{\circledR}$ is a registered trademark of Areva NP.
} 
$\mathrm{ZIRLO}^{72}, \mathrm{Zr}-1.2 \mathrm{Bi}-0.5 \mathrm{Nb}$ and modified Zircaloy-2 with $0.2 \% \mathrm{Nb}^{78}$ where accelerating factors between 1-2.5 were recorded. The differences in corrosion acceleration observed for the alloys in the current study due to the presence of a hydride rim is consistent with data available in the literature for the observed in-pile corrosion acceleration, suggesting that hydrogen build-up may indeed play an important role. Extrapolating further from ${ }^{14,72}$, the acceleration factor decreases with decreasing Sn content ( $<2$ for ZIRLO and no acceleration for $M 5^{\circledR}$ ), which also seems to be in agreement with the trends shown in the present study. It must be stated that using weight gain as the sole metric to project in-reactor behaviour at high burnup may lead to inaccurate comparisons as the weight gain reflects the average of the entire sample. Also, Second Phase Particle (SPP) evolution due to irradiation damage is a major factor in in-PWR corrosion performance of zirconium alloys, which is not evaluated by autoclave testing.

This comparison of hydrided and non-hydrided material has demonstrated that in most cases the hydride-rich rim has a detrimental effect on corrosion performance. However, the factor, by which the corrosion kinetics accelerates in the presence of a hydride-rich rim, is different for each alloy. Most explanations to date for the accelerated rate of corrosion in the presence of hydride-rich rims would suggest that acceleration should be independent of the alloy. This is clearly not the case from the data presented here. Detailed characterisation of the oxide and metal/oxide interface is necessary to identify the mechanisms by which the hydride-rich rim affects corrosion. 


\section{Summary}

Autoclave experiments were performed on Zircaloy-4, ZIRLO and two tin reduced variants of ZIRLO (A-0.6Sn, A-0.0Sn) with various heat treatment conditions. The corrosion weight gain was recorded as a function of the autoclave exposure time. In order to study the effect of a hydride-rich rim, ZIRLO, A-0.6Sn and A-0.0Sn tubes were also cathodically charged with hydrogen prior to autoclave exposure. The main findings can be summarised as follows:

- Standard Zr alloys exhibited typical corrosion kinetics with different time to reach transition depending on alloy type and metallurgical condition. The most significant difference was found between ZIRLO, A-0.6Sn and A-0.0Sn, where the time-to-transition increased systematically and significantly with decreasing Sn content. Sheet Zircaloy-4 exhibited similar transition time as sheet ZIRLO. Materials in a stress-relieved condition generally experienced the transition slightly earlier than materials in a recrystallised condition.

- The general corrosion kinetics prior to the transition were similar for most reference materials (i.e. cubic law), hence the factor dominating the corrosion performance for a single material is the time to reach transition.

- Cathodic hydriding facilitated the formation of a hydride-rich rim at the outer surface of cladding tubes, simulating end-of-life conditions of actual reactor fuel cladding. The accumulation of hydrides near the hydride/oxide interface and local hydrogen concentration are in good agreement with the reported conditions of actual samples from nuclear reactors ${ }^{51}$. 
- Most materials with a hydride-rich rim exhibited accelerated corrosion, with the extent of the acceleration being dependent on the type of alloy. The differences observed appear to be consistent with data available for high burnup zirconium cladding. For the recrystallised materials, alloys with higher tin content suffer more from the detrimental effect of a hydride-rich rim than low tin alloys. For ZIRLO and A-0.0Sn it is also observed that SR materials are more sensitive to the accelerating effect than $\mathrm{pRX}$ and $\mathrm{RX}$ materials, however this trend is not seen for A-0.6Sn. Despite the overall acceleration, in the initial stages of corrosion the measured weight gain increased more slowly for hydrided materials than for the reference samples. A relationship between the rate constant $K_{p}$ and kinetic exponent $n$ is observed in both hydrided and reference materials, regardless of the alloy chemistry and heat treatment.

- Further investigations are required before mechanistic explanation can be given. Current results suggest future studies should further investigate the effect of tin and the hydride-rich rim on the corrosion kinetics of zirconium alloys. 


\section{Acknowledgement}

The authors would like to thank the Engineering and Physical Science Research Council (EPSRC) and MoD in the UK for funding the research as part of the Materials for Energy call (research code: EP/E036171/1). The project would not have been possible without the strong support of our industrial project partners (in alphabetical order) EDF, National Nuclear Laboratory, Rolls-Royce, Serco and Westinghouse, who have provided substantial in-kind and financial support and our academic project partners from the University of Oxford and the Open University. 


\section{Figures and Tables}

Table 1: Measured chemical compositions of the materials involved in this study.

\begin{tabular}{lcccccccc}
\hline \multirow{2}{*}{ Alloy } & \multirow{2}{*}{$\begin{array}{c}\text { Heat } \\
\text { treatment }\end{array}$} & Geometry & \multicolumn{5}{c}{ Alloying Elements } & Hydrogen \\
\cline { 5 - 7 } & & & Fe[wt\%] & Sn[wt\%] & Nb[wt\%] & Cr[wt\%] & [wt.ppm] \\
\hline A-0.0Sn & $\mathrm{SRA}^{\mathrm{a}}, \mathrm{RX}^{\mathrm{c}}$ & tube & 0.10 & $<0.01$ & 1.00 & $<0.01$ & $<8$ \\
A-0.6Sn & $\mathrm{SR}, \mathrm{pRX} \mathrm{b}^{\mathrm{b}} \& \mathrm{RX}$ & tube & 0.09 & 0.66 & 0.91 & $<0.01$ & $4 \pm 1$ \\
ZIRLO & $\mathrm{SR}, \mathrm{RX}$ & tube & 0.09 & 0.92 & 0.91 & $<0.01$ & $10 \pm 4$ \\
ZIRLO & $\mathrm{SR}, \mathrm{RX}$ & sheet & 0.09 & 0.94 & 0.92 & $<0.01$ & $27 \pm 8$ \\
Zircaloy 4 A & $\mathrm{SR}, \mathrm{RX}$ & sheet & 0.17 & 1.24 & $<0.01$ & 0.10 & $12 \pm 3$ \\
Zircaloy 4 B & $\mathrm{RX}$ & sheet & 0.19 & 1.37 & $<0.01$ & 0.09 & $6 \pm 3$ \\
\hline
\end{tabular}

a: SR = Stress Relieved.

$\mathrm{b}: \mathrm{pRX}=$ partially Recrystallised.

c: $\mathrm{RX}=$ Recrystallised.

Table 2: Autoclave corrosion weight gain results of non-hydrided reference materials.

\begin{tabular}{|c|c|c|c|c|c|c|c|}
\hline \multirow[b]{2}{*}{ Alloy } & \multicolumn{3}{|c|}{ pre - Trans Kinetics } & \multicolumn{2}{|c|}{$1^{\text {st }}$ Trans } & \multirow{2}{*}{$\begin{array}{l}\text { Max. t } \\
\text { (days) }\end{array}$} & \multirow{2}{*}{$\begin{array}{l}\text { Max. } \Delta W \\
\left(\mathrm{mg} / \mathrm{dm}^{2}\right)\end{array}$} \\
\hline & $K_{\mathrm{p}}$ & $\mathrm{n}$ & $R^{2}$ & $\mathrm{t}$ (days) & $\underset{\left(\mathrm{mg} / \mathrm{dm}^{2}\right)}{\Delta \mathrm{W}}$ & & \\
\hline A-0.0Sn - SR & 5.381 & 0.365 & 0.993 & $>360$ & $>45^{\mathrm{a}}$ & 540 & $72.8 \pm 0.9$ \\
\hline$A-0.0 S n-R X$ & 4.693 & 0.383 & 0.989 & $>360$ & $>46^{\mathrm{a}}$ & 540 & $78.7 \pm 0.8$ \\
\hline A-0.6Sn-SR & 6.570 & 0.319 & 0.979 & 220 & $36.5 \pm 2.4$ & 260 & $47.5 \pm 3.2$ \\
\hline$A-0.6 S n-p R X$ & 6.595 & 0.311 & 0.977 & 260 & $38.2 \pm 2.5$ & 320 & $43.6 \pm 2.9$ \\
\hline$A-0.6 S n-R X$ & 5.935 & 0.344 & 0.985 & $140-240$ & $32.9 \pm 2.2$ & 260 & $56.2 \pm 3.7$ \\
\hline ZIRLO - SR & 6.262 & 0.339 & 0.938 & 120 & $32.8 \pm 2.2$ & 140 & $41.7 \pm 2.8$ \\
\hline ZIRLO - RX & 5.848 & 0.339 & 0.968 & 140 & $31.2 \pm 2.1$ & 160 & $43.2 \pm 2.9$ \\
\hline sheet ZIRLO - SR & 6.934 & 0.317 & 0.965 & 100 & $32.3 \pm 2.2$ & 160 & $56.0 \pm 3.7$ \\
\hline sheet ZIRLO - RX & 5.247 & 0.364 & 0.923 & 120 & $31.1 \pm 2.1$ & 140 & $41.7 \pm 2.8$ \\
\hline Zircaloy 4 A - SR & 8.179 & 0.275 & 0.974 & 120 & $31.4 \pm 2.1$ & 160 & $49.7 \pm 3.3$ \\
\hline Zircaloy 4 A - RX & 4.099 & 0.368 & 0.941 & 160 & $28.1 \pm 1.9$ & 220 & $50.1 \pm 3.3$ \\
\hline Zircaloy 4 B - RX & 5.728 & 0.331 & 0.959 & 140 & $30.4 \pm 2.0$ & 160 & $39.9 \pm 2.7$ \\
\hline
\end{tabular}


Table 3: Autoclave corrosion weight gain results of hydrided materials.

\begin{tabular}{|c|c|c|c|c|c|c|}
\hline \multirow{2}{*}{ Alloy } & \multicolumn{3}{|c|}{80 days $\Delta \mathrm{W}\left(\mathrm{mg} / \mathrm{dm}^{2}\right)$} & \multicolumn{3}{|c|}{ Corrosion Kinetics } \\
\hline & reference & hydrided & $\begin{array}{l}\text { hydrided/reference } \\
\text { ratio }\end{array}$ & $\mathrm{K}_{\mathrm{p}}$ & $\mathrm{n}$ & $R^{2}$ \\
\hline $\mathrm{A}-0.0 \mathrm{Sn}-\mathrm{SR}$ & $26.1 \pm 1.7$ & $34.8 \pm 2.0$ & 1.3 & 7.018 & 0.364 & 0.928 \\
\hline A- $0.0 S n-R X$ & $24.4 \pm 1.6$ & $26.7 \pm 0.9$ & 1.1 & 2.774 & 0.530 & 0.930 \\
\hline A-0.6Sn - SR & $26.9 \pm 1.8$ & $35.0 \pm 1.2$ & 1.3 & 4.331 & 0.474 & 0.981 \\
\hline A- $0.6 S n-p R X$ & $25.5 \pm 1.7$ & $27.5 \pm 2.3$ & 1.1 & 2.798 & 0.520 & 0.923 \\
\hline A-0.6Sn - RX & $26.8 \pm 1.8$ & $38.6 \pm 0.7$ & 1.4 & 3.790 & 0.539 & 0.949 \\
\hline ZIRLO - SR & $27.4 \pm 1.8$ & $45.2 \pm 1.9$ & 1.7 & 2.223 & 0.685 & 0.952 \\
\hline ZIRLO - RX & $25.9 \pm 1.7$ & $38.2 \pm 1.7$ & 1.5 & 3.073 & 0.588 & 0.801 \\
\hline
\end{tabular}

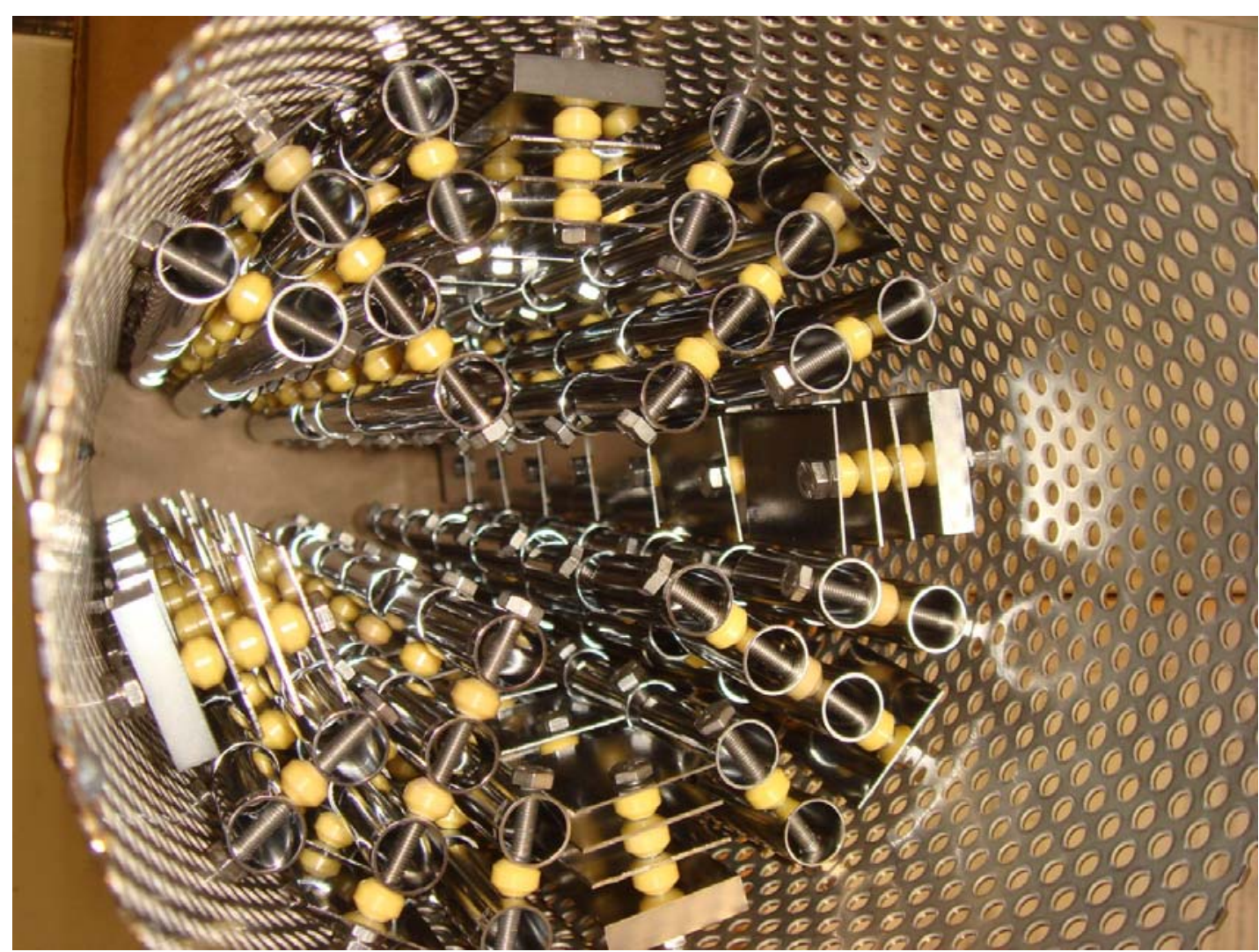

Figure 1: Autoclave basket showing all samples installed before autoclave exposure. The location of individual samples is kept unchanged. 


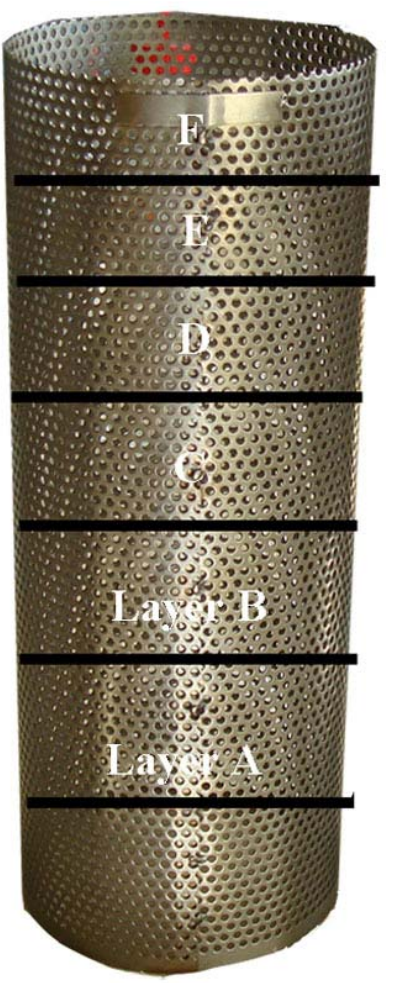

Side View

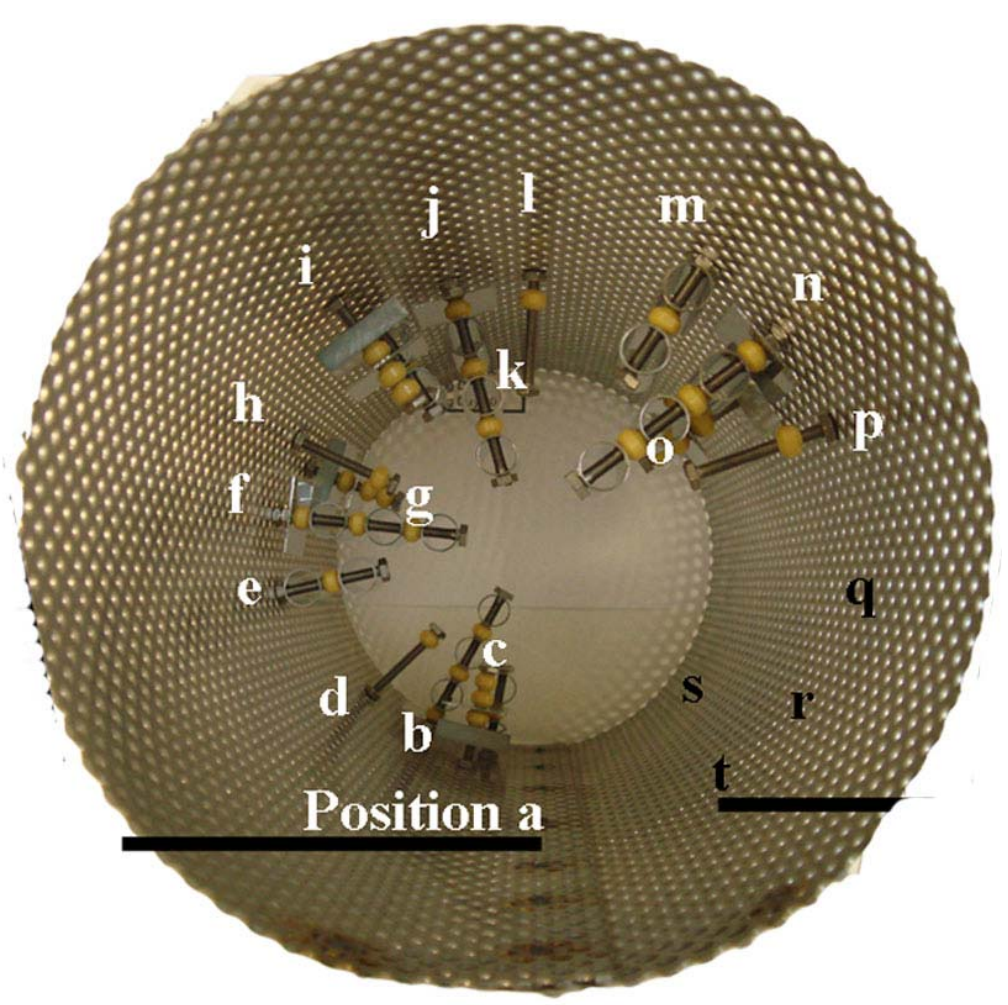

Top View
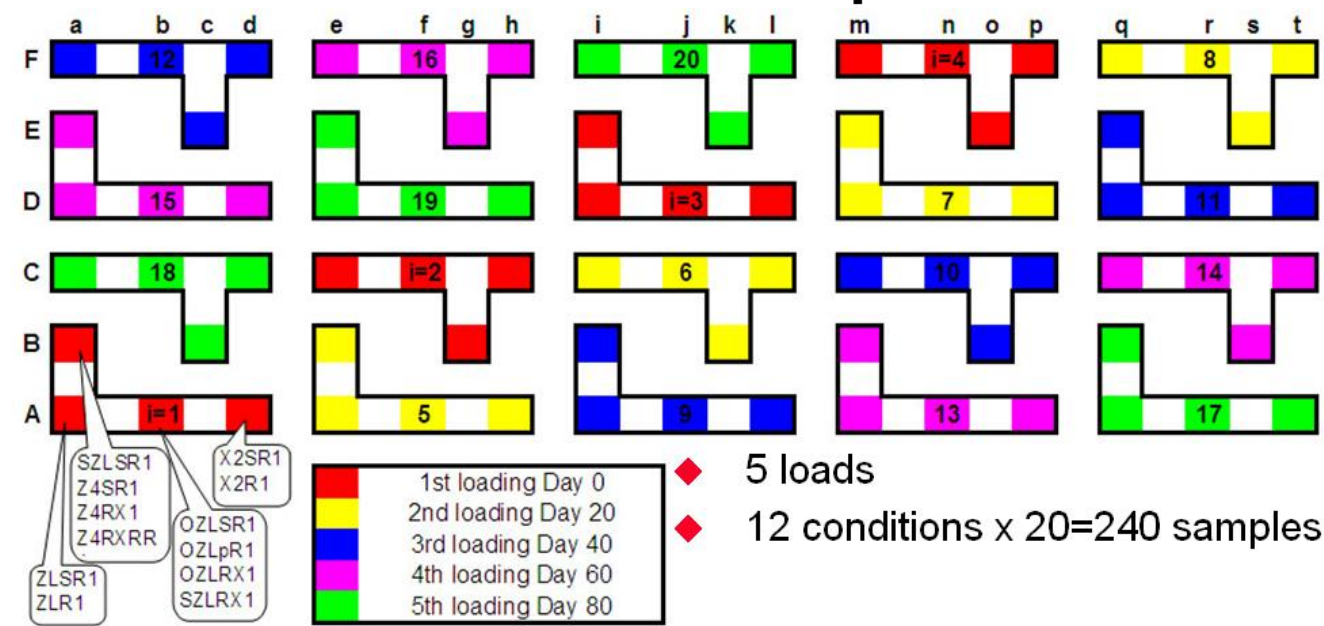

1st loading Day 0 5 loads $\begin{aligned} & \text { 2nd loading Day } 20 \\ & \text { 3rd loading Day } 40\end{aligned}-\quad 12$ conditions $\times 20=240$ samples 4 th loading Day 60 5 th loading Day 80

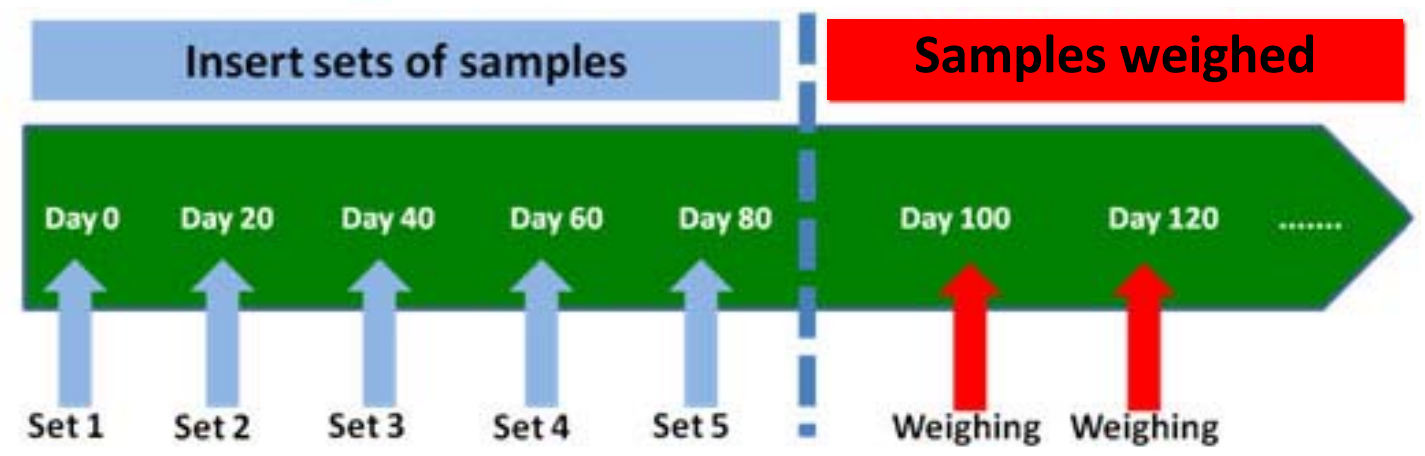

Figure 2: Sample allocation inside the autoclave basket and autoclave test scheme. 


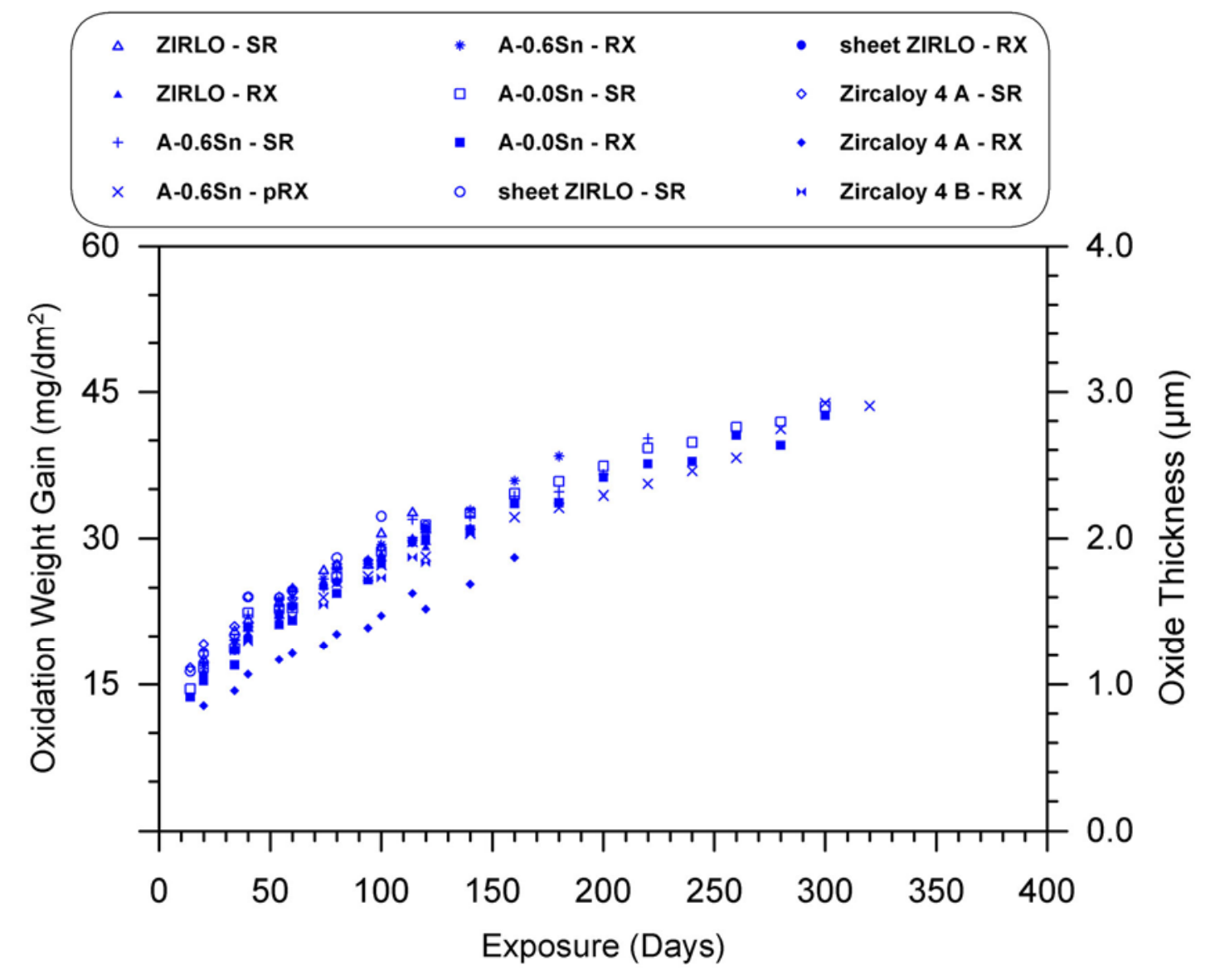

Figure 3: Summary of the Autoclave corrosion weight gain profiles showing the averaged pre-transition weight gain values for all 12 non-hydrided materials. 

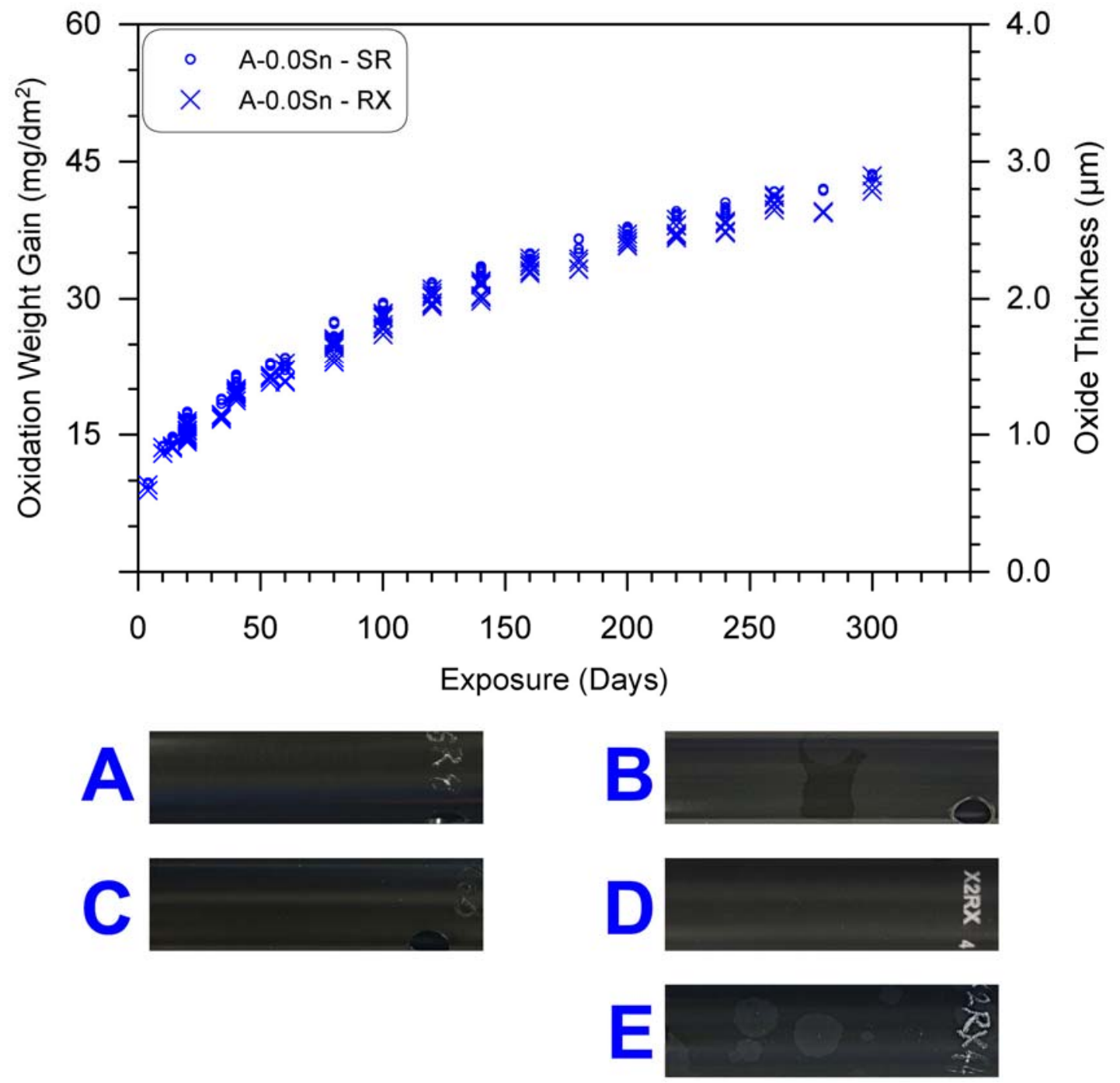

Figure 4: Autoclave corrosion weight gain profile of non-hydrided A-0.0Sn SR and RX materials. Photographs of actual corrosion specimens included: (A) non-hydrided A0.0Sn - SR after 280 days of autoclave exposure, (B) non-hydrided A-0.0Sn - SR after 540 days, (C) non-hydrided A-0.0Sn - RX after 20 days, (D) non-hydrided A$0.0 S n$ - RX after 300 days and (E) non-hydrided A-0.0Sn - RX after 540 days of autoclave exposure. 

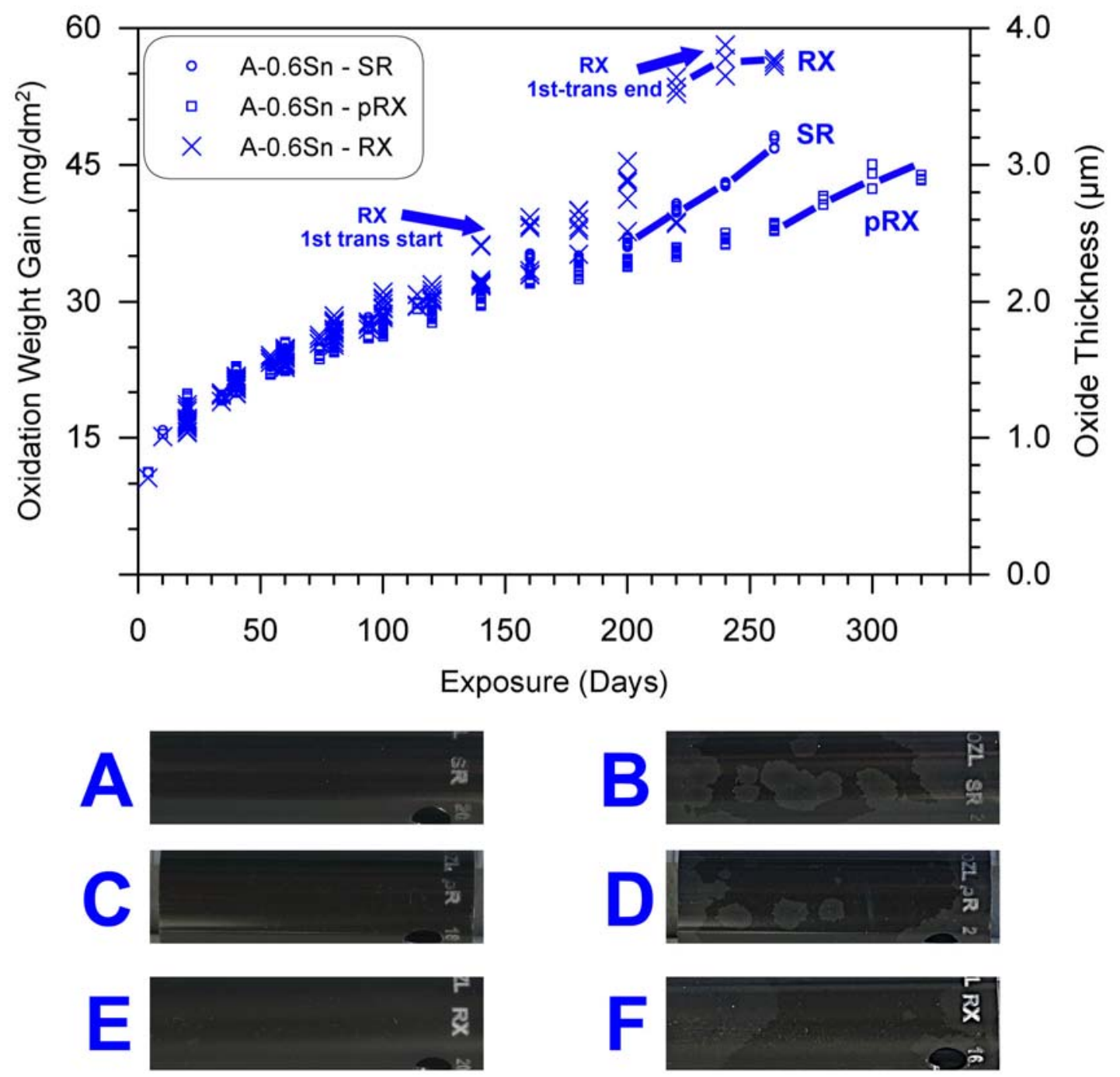

Figure 5: Autoclave corrosion weight gain profile of non-hydrided A-0.6Sn SR, pRX and RX materials. Photographs of actual corrosion specimens included: $(A)$ nonhydrided A-0.6Sn - SR after 180 days of autoclave exposure, (B) non-hydrided A$0.6 \mathrm{Sn}$ - SR after 260 days, (C) non-hydrided A-0.6Sn - pRX after 240 days, (D) nonhydrided A-0.6Sn - pRX after 320 days, (E) non-hydrided A-0.6Sn - RX after 180 days and (F) non-hydrided A-0.6Sn - RX after 200 days of autoclave exposure. 


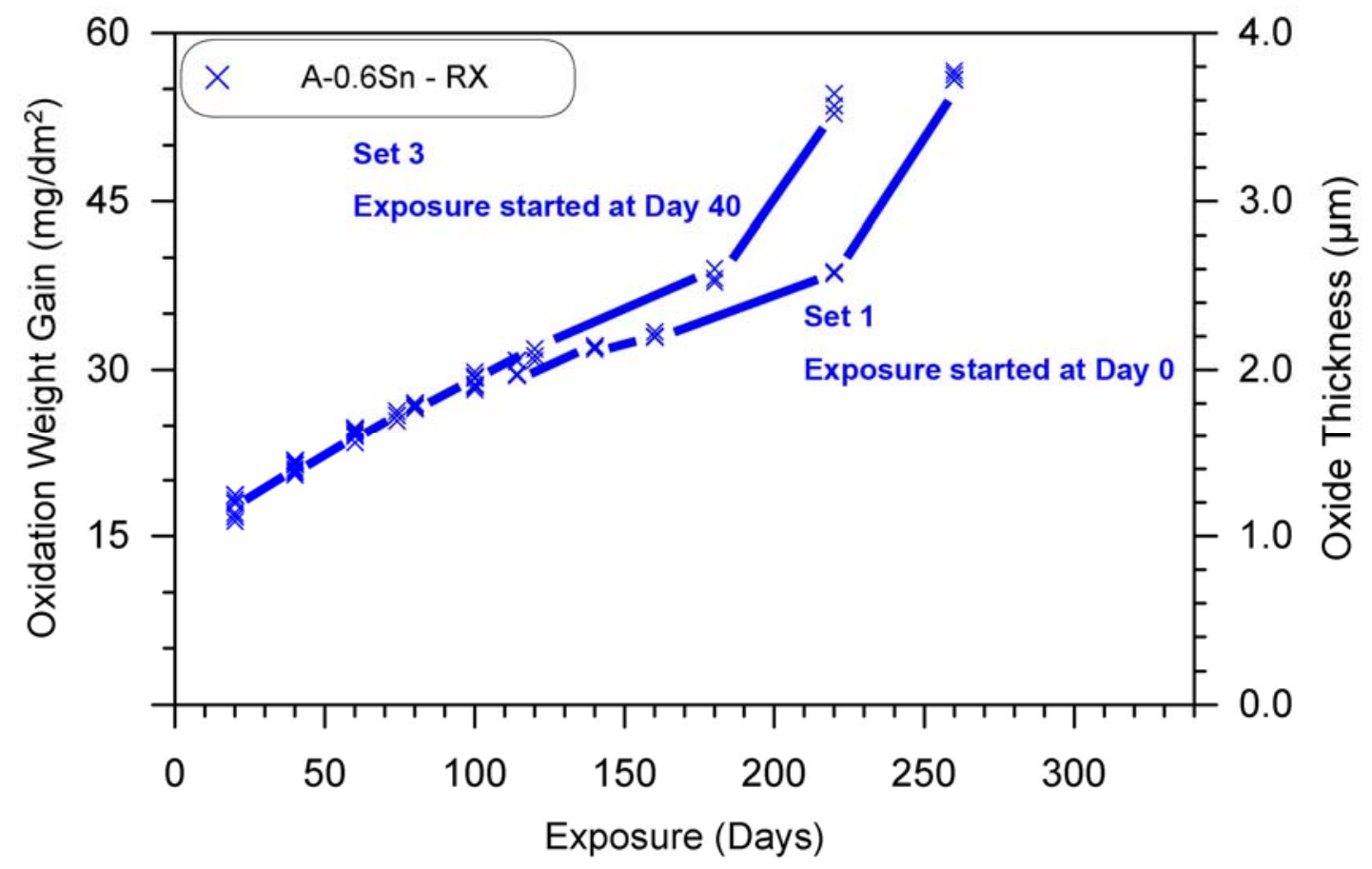

Figure 6: Autoclave corrosion weight gain profile of non-hydrided A-0.6Sn RX material. Highlighting the differences between different sets of samples, only data from set 1 and 3 is plotted here. 

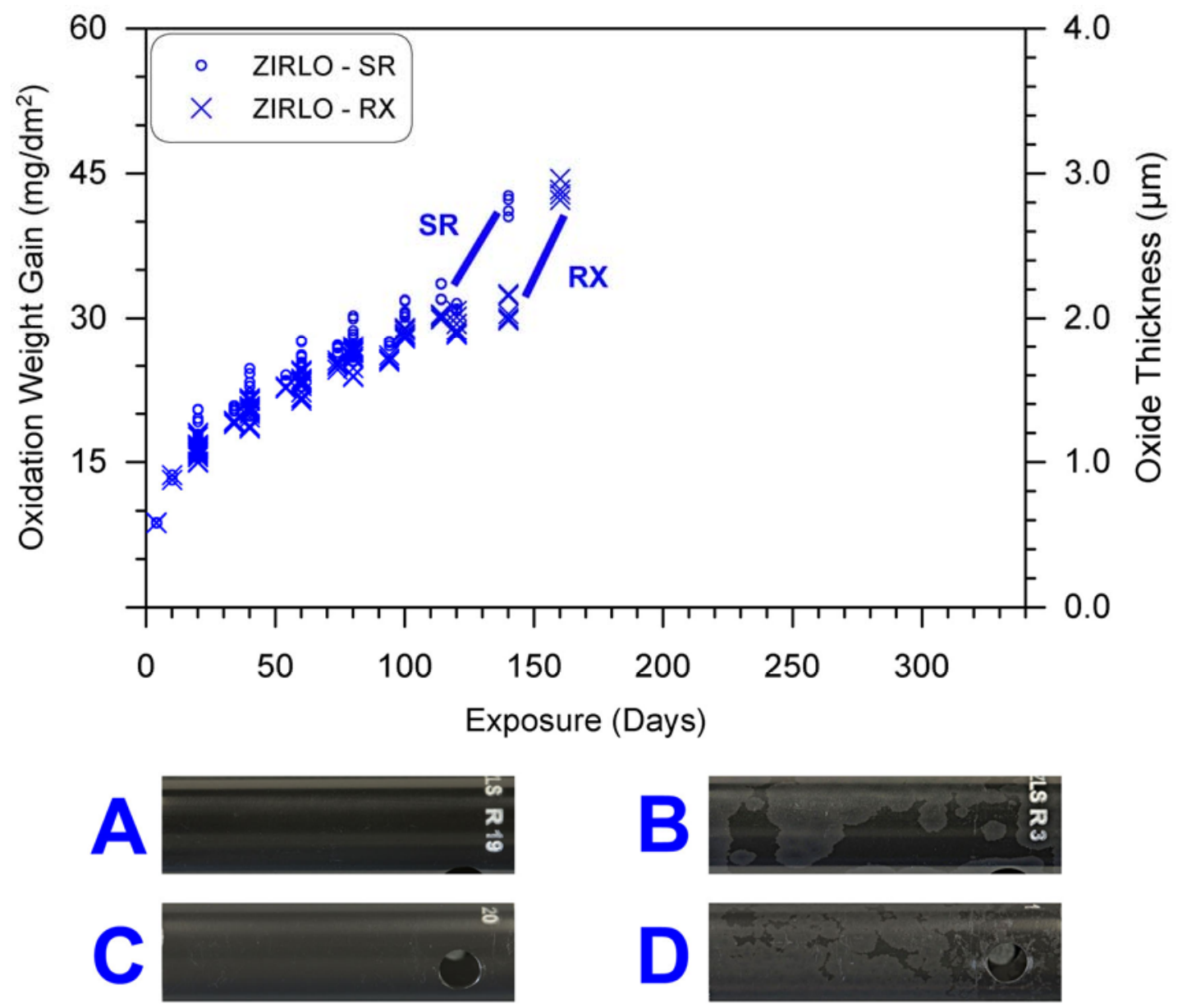

Figure 7: Autoclave corrosion weight gain profile of non-hydrided ZIRLO SR and RX materials. Photographs of actual corrosion specimens included: (A) non-hydrided ZIRLO - SR after 60 days of autoclave exposure, (B) non-hydrided ZIRLO - SR after 140 days, (C) non-hydrided ZIRLO - RX after 80 days and (D) non-hydrided ZIRLO RX after 160 days. 

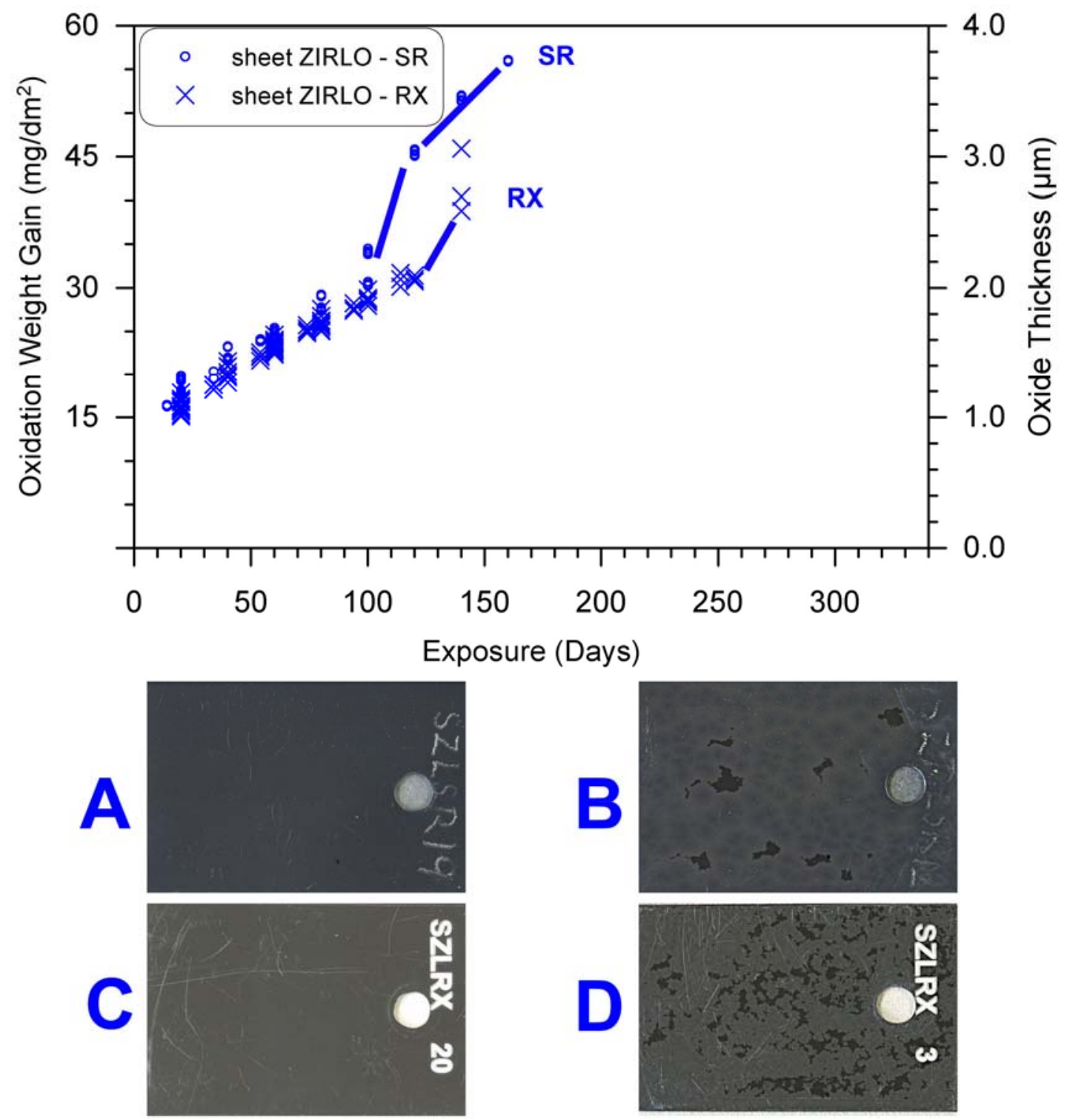

Figure 8: Autoclave corrosion weight gain profile of non-hydrided sheet ZIRLO SR and RX materials. Photographs of actual corrosion specimens included: (A) nonhydrided sheet ZIRLO - SR after 80 days of autoclave exposure, (B) non-hydrided sheet ZIRLO - SR after 120 days, (C) non-hydrided sheet ZIRLO - RX after 60 days and (D) non-hydrided sheet ZIRLO - RX after 140 days. 

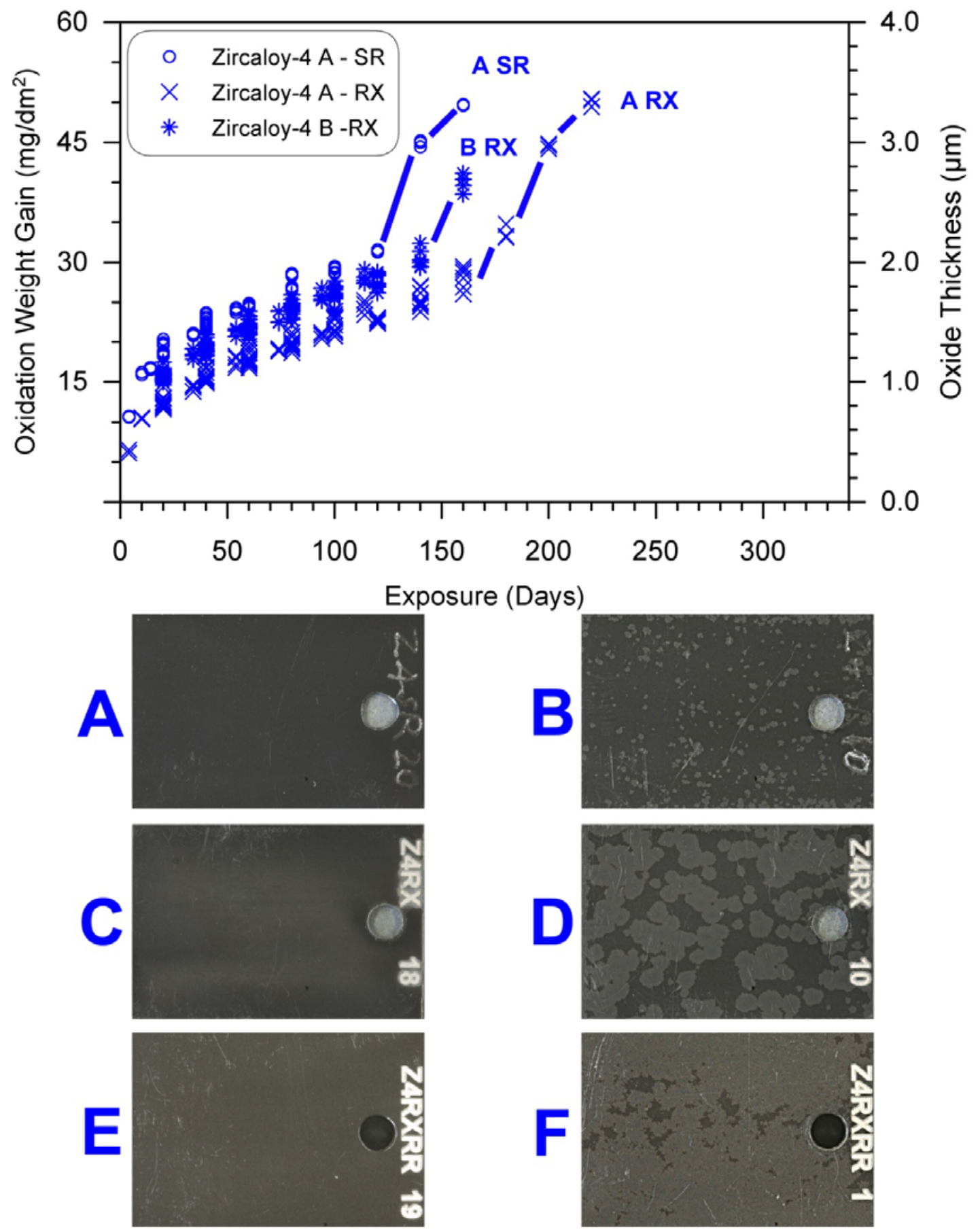

Figure 9: Autoclave corrosion weight gain profile of non-hydrided Zircaloy-4 A SR, RX and Zircaloy-4 B - RX materials. Photographs of actual corrosion specimens included: (A) non-hydrided Zircaloy-4 A - SR after 80 days of autoclave exposure, (B) non-hydrided Zircaloy-4 A - SR after 120 days, (C) non-hydrided Zircaloy-4 A - RX after 140 days, (D) non-hydrided Zircaloy-4 A - RX after 180 days, (E) non-hydrided Zircaloy-4 B - RX after 80 days and (E) non-hydrided Zircaloy-4 B - RX after 160 days of autoclave exposure. 


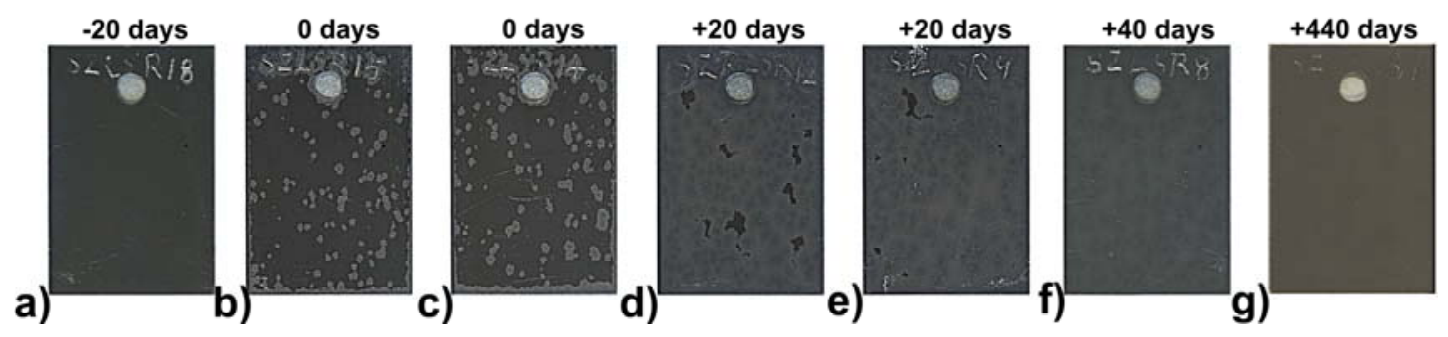

Figure 10: Photographs of sheet ZIRLO - SR corroded specimens demonstrating the progression of transition, the number of days above the photos indicate the time to or after transition, transition occurred after 100 days of exposure: (a) transition -20 days, (b) and (c) onset of transition, (d) and (e) transition +20 days, ( $f$ ) transition + 40 days and $(\mathrm{g})$ transition +440 days of autoclave exposure. 


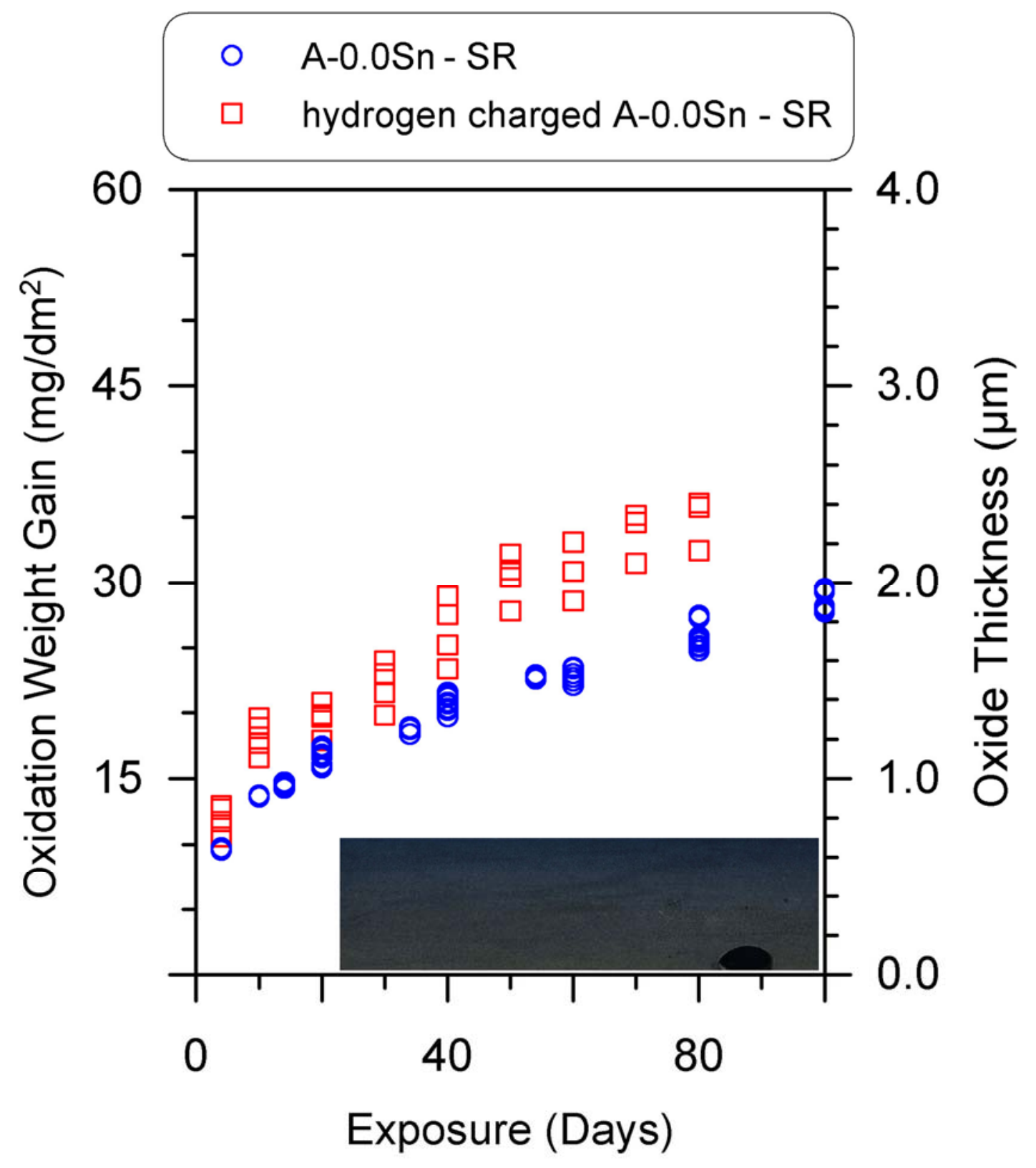

Figure 11: Autoclave corrosion weight gain profiles of hydrided A-0.0Sn - SR, over all $[\mathrm{H}]$ around 700 wt.ppm and non-hydrided A-0.0Sn - SR samples. Photographs of actual corrosion specimens inserted: hydrided A-0.0Sn - SR after 40 days of autoclave exposure. 


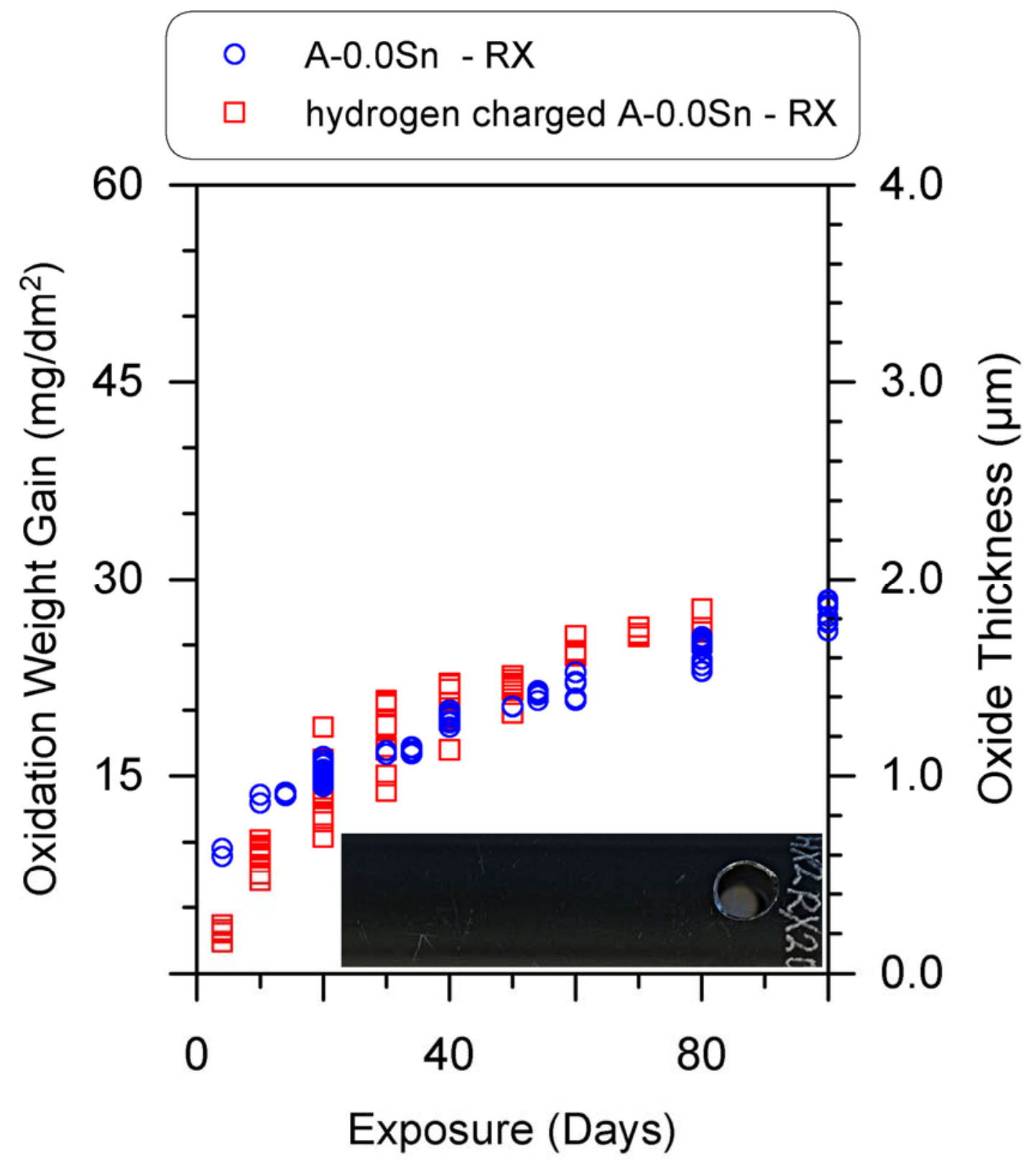

Figure 12: Autoclave corrosion weight gain profiles of hydrided A-0.0Sn - RX, over all $[\mathrm{H}]$ around 600 wt.ppm and non-hydrided A-0.0Sn - RX samples. Photographs of actual corrosion specimens inserted: hydrided A-0.0Sn - RX after 40 days of autoclave exposure. 


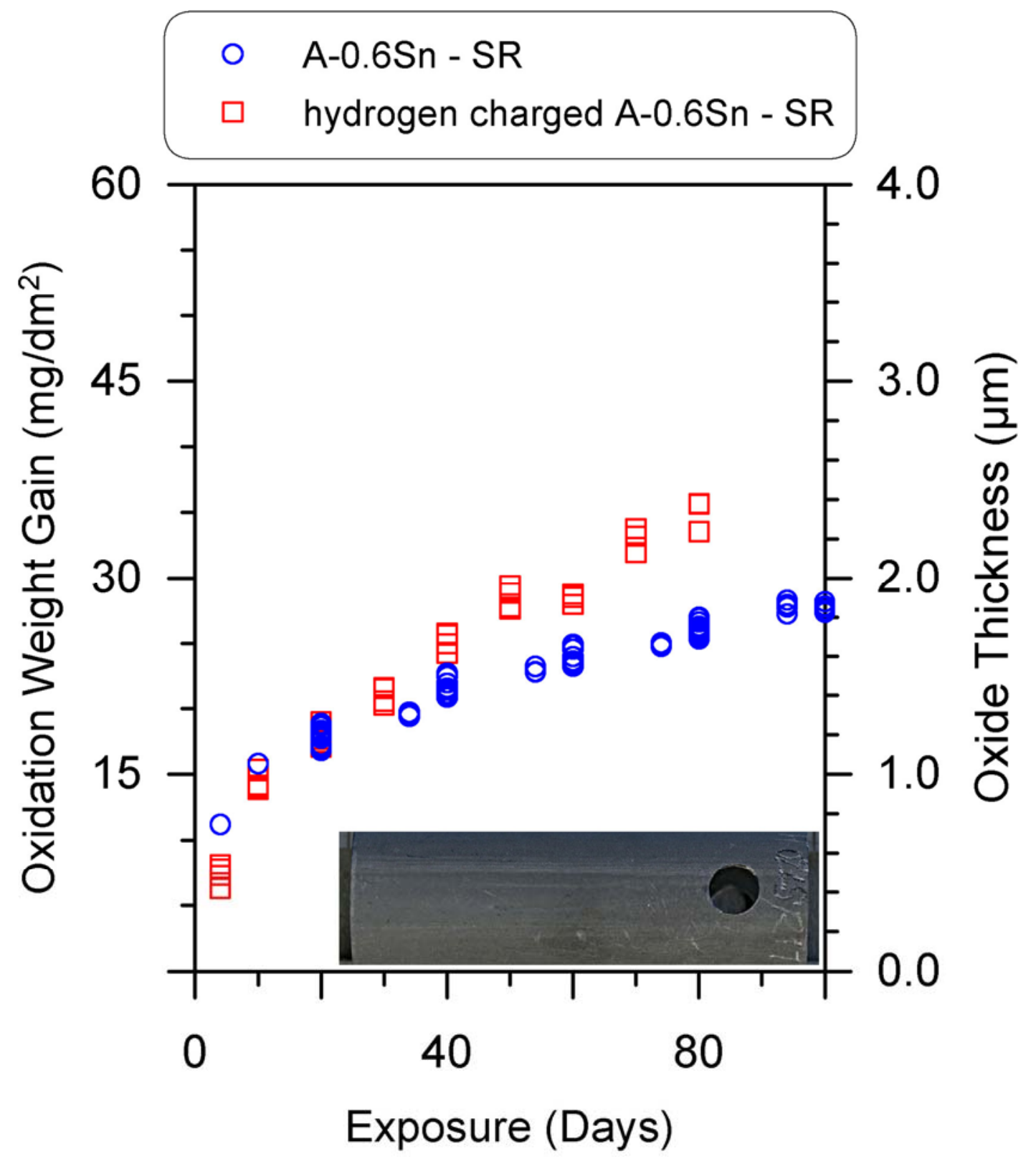

Figure 13: Autoclave corrosion weight gain profiles of hydrided A-0.6Sn - SR, over all $[\mathrm{H}]$ around 700 wt.ppm and non-hydrided A-0.6Sn - SR samples. Photographs of actual corrosion specimens inserted: hydrided A-0.6Sn - SR after 40 days of autoclave exposure. 


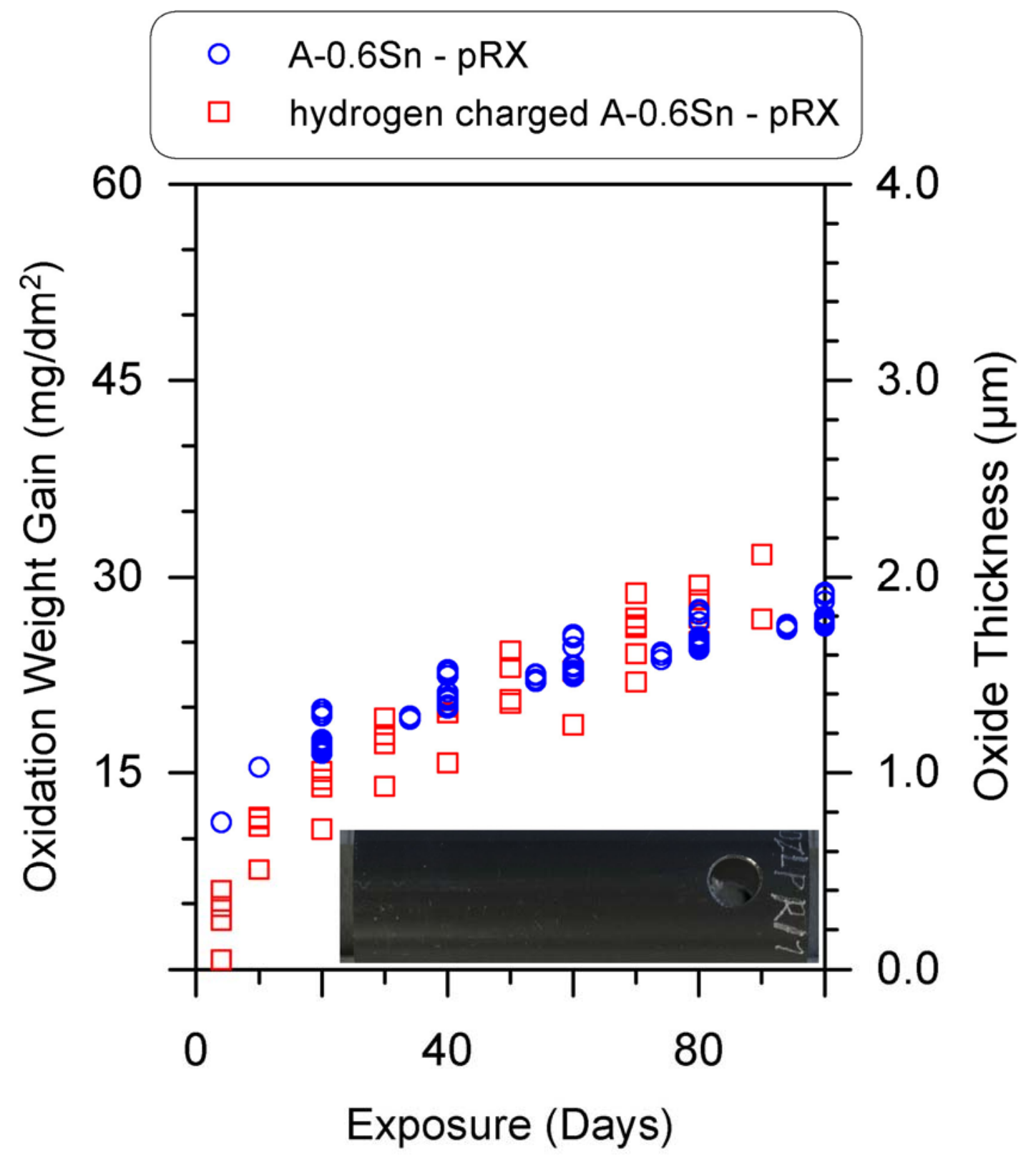

Figure 14: Autoclave corrosion weight gain profiles of hydrided A-0.6Sn - pRX, over all $[\mathrm{H}]$ around 700 wt.ppm and non-hydrided A-0.6Sn - pRX samples. Photographs of actual corrosion specimens inserted: hydrided A-0.6Sn - pRX after 40 days of autoclave exposure. 


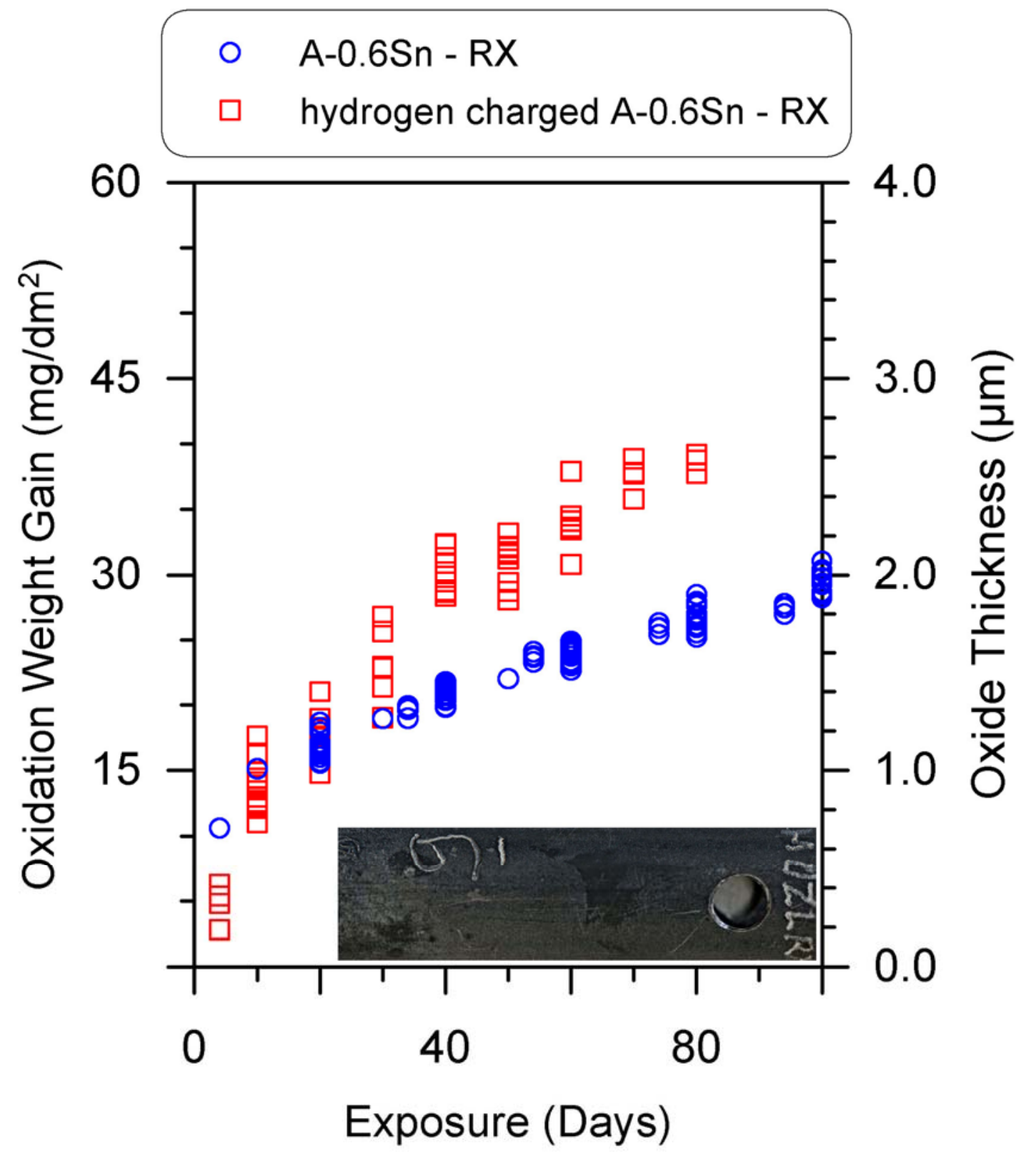

Figure 15: Autoclave corrosion weight gain profiles of hydrided A-0.6Sn - RX, over all $[\mathrm{H}]$ around 650 wt.ppm and non-hydrided A-0.6Sn - RX samples. Photographs of actual corrosion specimens inserted: hydrided A-0.6Sn - RX after 40 days of autoclave exposure. 


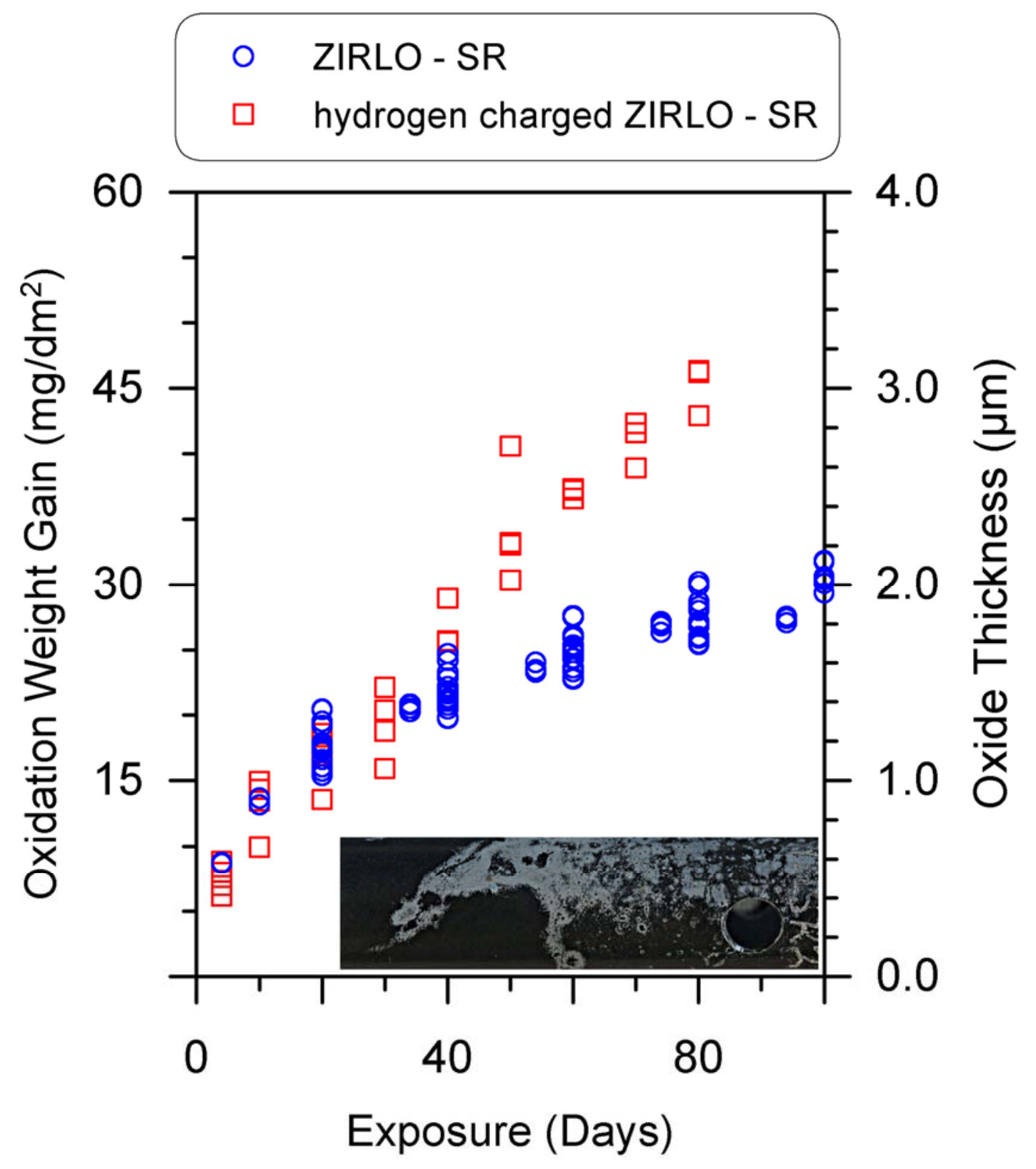

Figure 16: Autoclave corrosion weight gain profiles of hydrided ZIRLO - SR, over all [H] around 700 wt.ppm and non-hydrided ZIRLO - SR samples. Photographs of actual corrosion specimens inserted: hydrided ZIRLO - SR after 40 days of autoclave exposure. 


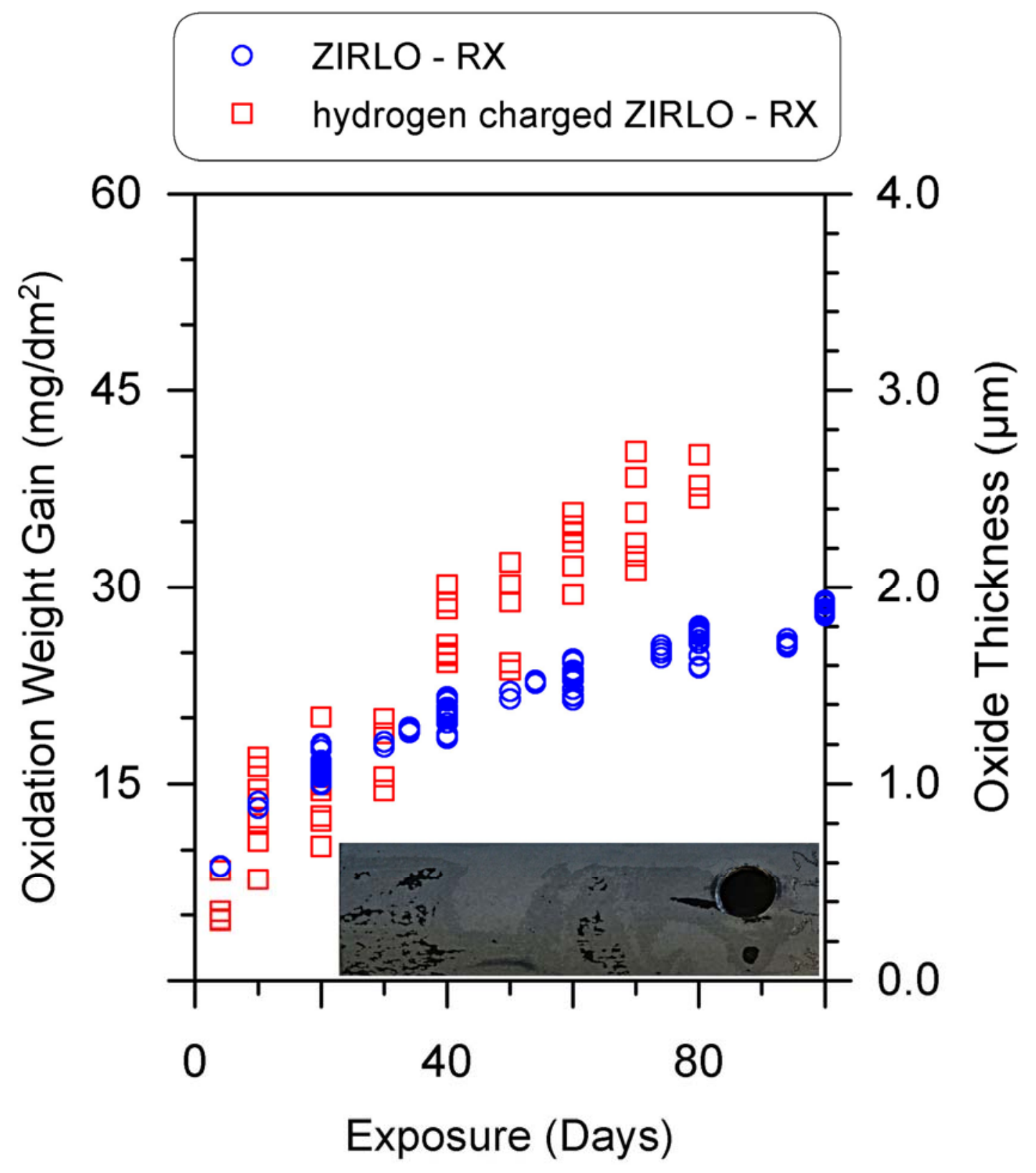

Figure 17: Autoclave corrosion weight gain profiles of hydrided ZIRLO - RX, over all $[\mathrm{H}]$ around 700 wt.ppm and non-hydrided ZIRLO - RX samples. Photographs of actual corrosion specimens inserted: hydrided ZIRLO - RX after 40 days of autoclave exposure. 


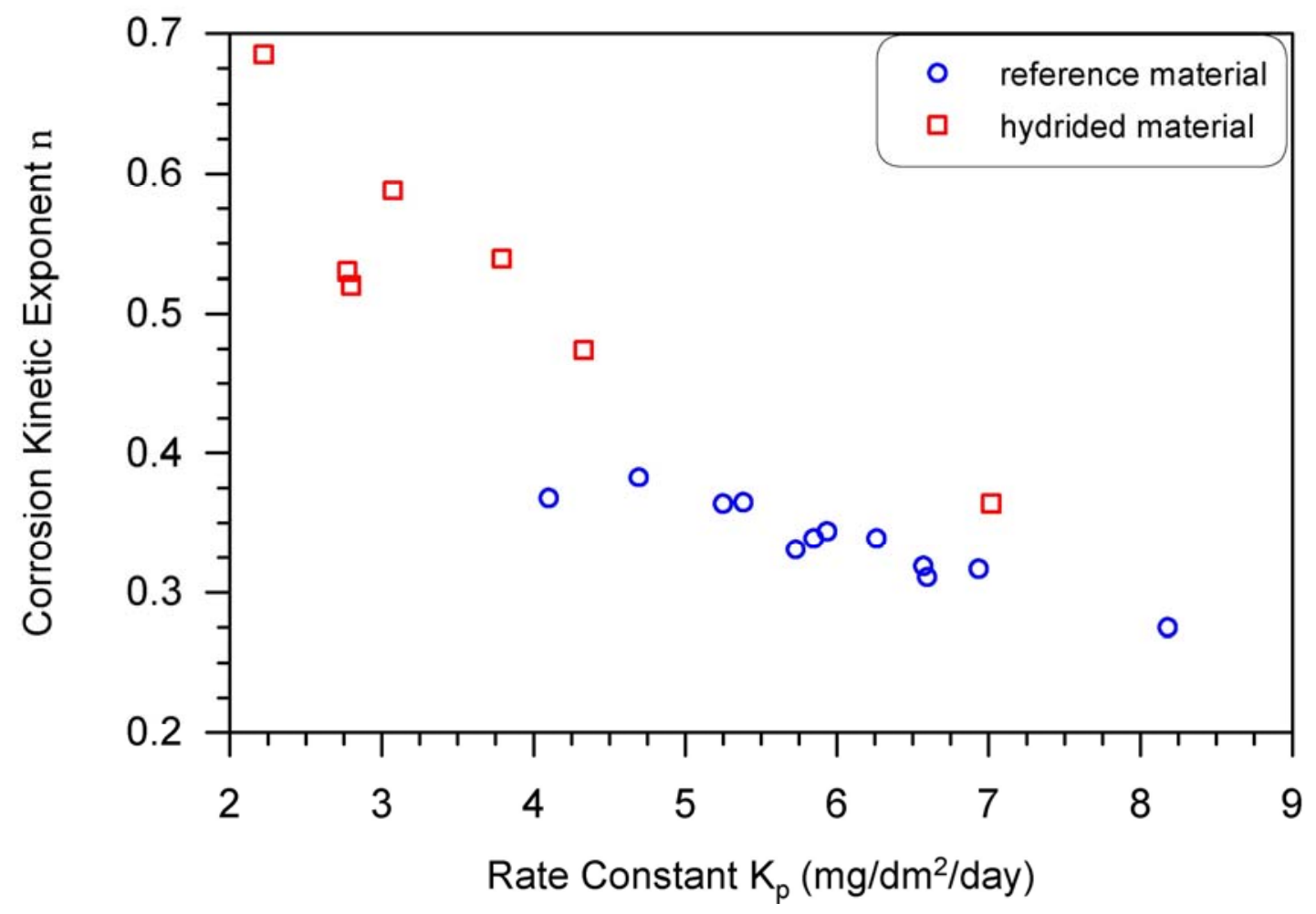

Figure 18: Corrosion kinetic exponent $n$ plotted as a function of the rate constant $K_{p}$. Data involves all alloys and heat treatment conditions as well as their hydrogen charged counter parts. 


\section{References}

1. T. Arima, K. Miyata, Y. Inagaki, and K. Idemitsu: 'Oxidation properties of $\mathrm{Zr}-\mathrm{Nb}$ alloys at $500-600{ }^{\circ} \mathrm{C}$ under low oxygen potentials', Corrosion Science, 2005, 47(2), 435-446.

2. T. Arima, K. Moriyama, N. Gaja, H. Furuya, K. Idemitsu, and Y. Inagaki: 'Oxidation kinetics of Zircaloy- 2 between $450^{\circ} \mathrm{C}$ and $600^{\circ} \mathrm{C}$ in oxidizing atmosphere', Journal of Nuclear Materials, 1998, 257(1), 67-77.

3. J. S. Bryner: 'The cyclic nature of corrosion of zircaloy-4 in $633 \mathrm{~K}$ water', Journal of Nuclear Materials, 1979, 82(1), 84-101.

4. B. Cox: 'Comments on "aqueous corrosion of the Zircaloys at low temperatures"', Journal of Nuclear Materials, 1969, 30(3), 351-352.

5. B. Cox: 'Some thoughts on the mechanisms of in-reactor corrosion of zirconium alloys', Journal of Nuclear Materials, 2005, 336(2-3), 331-368.

6. B. Griggs, H. P. Maffei, and D. W. Shannon: 'Multiple Rate Transitions in the Aqueous Corrosion of Zircaloy', Journal of The Electrochemical Society, 1962, 109(8), 665-668.

7. K. Hauffe: 'Oxidation of metals'; 1965, New York, Plenum Press, Inc.

8. S. Kass: 'The Development of the Zircaloys', Corrosion of Zirconium Alloys, ANS Winter meeting, 1964, ASTM International.

9. S. Kass: 'Aqueous corrosion of the zircaloys at low temperatures', Journal of Nuclear Materials, 1969, 29(3), 315-321.

10. A. A. Kiselev, V. A. Myshkin, A. V. Kozhevnikov, S. L. Korolev, and E.G. Shorina: 'Corrosion of Reactor Materials'; 1962, Vienna IAEA.

11. B. Lustman and F. K. Jr: 'The Metallurgy of zirconium', 776; 1955, New York, McGraw-Hill.

12. A. T. Motta, M. J. G. D. Silva, A. Yilmazbayhan, R. J. Comstock, Z. Cai, and B. Lai: 'Micostructural characterisation of oxides formed on model $\mathrm{Zr}$ alloys using synchrotron radiation', 15th International Symposium on Zirconium in the Nuclear Industry, Sunriver Resort Oregon, USA, 24-28 June 2007, 2009, ASTM International 486-506.

13. G. P. Sabol and S. B. Dalgaard: 'The Origin of the Cubic Rate Law in Zirconium Alloy Oxidation', Journal of The Electrochemical Society, 1975, 122(2), 316-317.

14. P. Bossis, D. Pêcheur, K. Hanifi, J. Thomazet, and M. Blat: 'Comparison of the High Burn-Up Corrosion on M5 and Low Tin Zircaloy-4', 14th International Symposium on Zirconium in the Nuclear Industry, Stockholm, Sweden, 13-17 June 2004, 2005, ASTM International, 494-525.

15. P. Bouvier, J. Godlewski, and G. Lucazeau: 'A Raman study of the nanocrystallite size effect on the pressure-temperature phase diagram of zirconia grown by zirconium-based alloys oxidation', Journal of Nuclear Materials, 2002, 300(2-3), 118-126.

16. A. M. Garde: 'Enhancement of Aqueous Corrosion of Zircaloy-4 Due to Hydride Precipitation at the Metal-Oxide Interface', 9th International Symposium on Zirconium in the Nuclear Industry, Kobe, Japan, 5-8 November 1990, 1991, ASTM International, 566-592.

17. J. Godlewski: 'How the tetragonal zirconia is stabilized in the oxide scale that is formed on a zirconium alloy corroded at $400^{\circ} \mathrm{C}$ in steam', 10th International Symposium on Zirconium in the Nuclear Industry: , Baltimore, MD, 21-24 June 1993, 1994, ASTM International, 663-683. 
18. H. R. Peters: 'Improved Characterization of Aqueous Corrosion Kinetics of Zircaloy4', 6th International Symposium on Zirconium in the Nuclear Industry, Vancouver, British Columbia, Canada, 1982, 1984, ASTM International, 507-519.

19. A. Yilmazbayhan, A. T. Motta, R. J. Comstock, G. P. Sabol, B. Lai, and Z. Cai: 'Structure of zirconium alloy oxides formed in pure water studied with synchrotron radiation and optical microscopy: relation to corrosion rate', Journal of Nuclear Materials, 2004, 324(1), 6-22.

20. M. Preuss, P. Frankel, S. Lozano-Perez, D. Hudson, E. Polatidis, N. Ni, J. Wei, C. English, S. Storer, K. B. Chong, M. Fitzpatrick, F. Wang, J. Smith, C. Grosvenor, G. Smith, J. Sykes, A. Cerezo, B. Cottis, S. Lyon, L. Hallstadius, B. Comstock, A. Ambard, and M. Blat-Yrieix: 'Towards a mechanistic understanding of corrosion mechanisms in zirconium alloys', 16th International Symposium on Zirconium in the Nuclear Industry, ChengDu, P.R.China, May, 2010, 2010, ASTM International

21. M. Blat-Yrieix, A. Ambard, F. Foct, A. Miquet, S. Beguin, and N. Cayet: 'Toward a Better Understanding of Dimensional Changes in Zircaloy-4: What is the Impact Induced by Hydrides and Oxide Layer?', Journal of ASTM International (JAI), 2008, 5(9), 16.

22. V. Busser, J. Desquines, S. Fouquet, M. C. Baietto, and J. P. Mardon: 'Modelling of Corrosion Induced Stresses during Zircaloy-4 Oxidation in Air', Materials Science Forum, 2008, 595-598, 419-427.

23. C. Roy and B. Burgess: 'A study of the stresses generated in zirconia films during the oxidation of zirconium alloys', Oxidation of Metals, 1970, 2(3), 235-261.

24. B. Cox: 'Are Zirconium Corrosion Films a Form of Partially Stablized Zirconia?', AECL9382, Atomic Energy of Canada Ltd, 1987.

25. J. Godlewski, P. Bouvier, G. Lucazeau, and L. Fayette: 'Stress Distribution Measured by Raman Spectroscopy in Zirconia Films Formed by Oxidation of Zr-Based Alloys', 12th International Symposium on Zirconium in the Nuclear Industry, Toronto, Canada, 15-18 June 1998, 2000, ASTM International, 877-899.

26. C. M. Schwartz, D. A. Vaughan, and G. G. Cocks: 'Report BMI-793 December 17, 1952. ', in 'The Metallurgy of Zirconium', (eds. B. Lustman, et al.), 562; 1955, New York, McGraw-Hill.

27. A. H. Heuer and M. Rühle: 'Overview no. 45: On the nucleation of the martensitic transformation in zirconia (ZrO2)', Acta Metallurgica, 1985, 33(12), 2101-2112.

28. R. A. Ploc and S. B. Newcomb: 'Microscopy of Oxidation 3', Third International Conference on the Microscopy of Oxidation, Trinity Hall, Cambridge, 1996, Institute of Materials, Minerals and Mining, 475-487.

29. B. Cox, V. G. Kritsky, C. Lemaignan, V. Polley, I. G. Ritchie, H. Ruhmann, V. N. Shishov, Y. K. Bibilashvili, and A. V. Nikulina: 'Waterside Corrosion of Zirconium Alloys in Nuclear Power Plants', TECDOC-996, IAEA, Vienna, 1998.

30. J. C. Clayton: 'Out-of-Pile Nickel Alloy-Induced Accelerated Hydriding of Zircaloy Fasteners', 6th International Symposium on Zirconium in the Nuclear Industry, Vancouver, British Columbia, Canada, 1982, ASTM International, 572-591.

31. A. M. Garde, G. P. Smith, and R. C. Pirek: 'In-PWR Irradiation Performance of Dilute Tin-Zirconium Advanced Alloys', 13th International Symposium on Zirconium in the Nuclear Industry, Annecy, France, 10-14 June 2001, 2002, ASTM International, 490506.

32. B. F. Kammenzind, D. G. Franklin, W. J. Duffin, and H. R. Peters: 'Hydrogen pickup and redistribution in alpha-annealed Zircaloy-4', 11th International Symposium on Zirconium in the Nuclear Industry, Garmisch-Partenkirchen, Germany, 11-14 Sept. 1995, 1996, ASTM International, 338-370. 
33. J. J. Kearns: 'Terminal solubility and partitioning of hydrogen in the alpha phase of zirconium, Zircaloy-2 and Zircaloy-4', Journal of Nuclear Materials, 1967, 22(3), 292303.

34. A. Mcminn, E. C. Darby, and J. S. Schofield: 'The Terminal Solid Solubility of Hydrogen in Zirconium Alloys', 12th International Symposium on Zirconium in the Nuclear Industry, Toronto, Canada, 15-18 June 1998, 2000, ASTM International, 173-196.

35. B. F. Kammenzind, B. M. Berquist, R. Bajaj, P. H. Kreyns, and D. G. Franklin: 'The Long Range Migration Of Hydrogen Through Zircaloy In Response To Tensile And Compressive Stress Gradients', 12th International Symposium on Zirconium in the Nuclear Industry, Toronto, Canada, 15-18 June 1998, 2000, ASTM International, 196-233.

36. M. Blat and D. Noel: 'Detrimental Role of Hydrogen on the Corrosion Rate of Zirconium Alloys', 11th International Symposium on Zirconium in the Nuclear Industry, Garmisch-Partenkirchen, Germany, 11-14 Sept. 1995, 1996, ASTM International, 319-337.

37. B. Cox and T. Johnson: 'Observation of a Second Transition Point During the Oxidation of Zirconium Alloys', in 'Corrosion', 33; 1962.

38. D. Khatamian: 'Role of hydrides on the oxidation and deuterium pickup of $\mathrm{Zr}-2.5 \mathrm{Nb}$ in D2O at 573 K', Journal of Alloys and Compounds, 2005, 404-406, 297-302.

39. T. Kido: 'A Study on Enhanced Uniform Corrosion of Zircaloy-4 cladding during High Burnup Operation in PWRs', 6th Internanional Symposium on Environmental Degradation of Materials in Nuclear Power Systems - Water Reactors, San Diego, California, USA, 1-5 August 1993, 1993, The minerals, Metals \& Materials Society, 449-456.

40. M. Blat, L. Legras, D. Noel, and H. Amanrich: 'Contribution to a Better Understanding of the Detrimental Role of Hydrogen on the Corrosion Rate of Zircaloy-4 Cladding Materials', 12th International Symposium on Zirconium in the Nuclear Industry, Toronto, Canada, 15-18 June 1998, 2000, ASTM International, 563-592.

41. G. J. C. Carpenter: 'The dilatational misfit of zirconium hydrides precipitated in zirconium', Journal of Nuclear Materials, 1973, 48(3), 264-266.

42. R. S. Daum, Y. S. Chu, and A. T. Motta: 'Identification and quantification of hydride phases in Zircaloy-4 cladding using synchrotron X-ray diffraction', Journal of Nuclear Materials, 2009, 392(3), 453-463.

43. J. R. Santisteban, M. A. Vicente-Alvarez, P. Vizcaíno, A. D. Banchik, and J. D. Almer: 'Hydride precipitation and stresses in zircaloy-4 observed by synchrotron X-ray diffraction', Acta Materialia, 2010, 58(20), 6609-6618.

44. Y. S. Kim, H. K. Woo, K. S. Im, and S. I. Kwun: 'The Cause for Enhanced Corrosion of Zirconium Alloys by Hydrides', 13th International Symposium on Zirconium in the Nuclear Industry, Annecy, France, 10-14 June 2001, 2002, ASTM International, 274295.

45. A. Seibold and F. Garzarolli: 'Influence of Composition and Condition on In-PWR Behavior of Zr-Sn-Nb-FeCrV alloys', 13th International Symposium on Zirconium in the Nuclear Industry, Annecy, France, 10-14 June 2001, 2002, ASTM International, 743-757.

46. A. M. Garde, S. R. Pati, M. A. Krammen, G. P. Smith, and R. K. Endter: 'Corrosion behavior of zircaloy-4 cladding with varying tin content in high-temperature pressurized water reactors', in 'Zirconium in the Nuclear Industry: Tenth International Symposium', (ed. A. M. B. E. R. Garde), 760-778; 1994. 
47. H. K. Yueh, R. L. Kesterson, R. J. Comstock, H. H. Shah, D. J. Colburn, M. Dahlback, and L. Hallstadius: 'Improved ZIRLO (TM) cladding performance through chemistry and process modifications', in 'Zirconium in the Nuclear Industry: 14th International Symposium', (ed. P. K. B. Rudling), 330-346; 2005.

48. R. L. Kesterson, K. Yueh, H. Shah, J. Foster, D. Colburn, L. Hallstadius, and I. Arana: 'Cladding Optimization for Enhanced Performance Margins', TOPFUEL 2006, Salamanca, Spain, 2006, 67.

49. G. P. Sabol, G. R. Kilp, M. G. Balfour, and E. Roberts: 'Development of a Cladding Alloy for High Burnup', ASTM STP 1023, 1989, 227-244.

50. H. P. Chabretou V., Trapp-Pritsching S., Garner G., Barberis P., Rebeyrolle V., Vermoyal J.: 'Ultra Low Tin Quaternary Alloys PWR Performance-Impact of Tin Content on Corrosion Resistance, Irradiation Growth, and Mechanical Properties', Journal of ASTM International 2011, 8(5).

51. J. Wei, P. Frankel, K. Govender, M. Blat, A. Ambard, R. J. Comstock, L. Hallstadius, S. Lyon, B. Cottis, and M. Preuss: 'Synthesis of a Hydride Rich Rim on Zirconium Alloys: A Cathodic Hydrogen Charging Method', Corrosion Science, 2011, To be Submitted.

52. B. Cheng, P. M. Gilmore, and H. H. Klepfer: 'PWR Zircaloy Fuel Cladding Corrosion Performance, Mechanisms, and Modeling', 11th International Symposium on Zirconium in the Nuclear Industry, Garmisch-Partenkirchen, Germany, 11-14 Sept. 1995, 1996, ASTM International, 137-160.

53. P. Barberis: 'Zirconia powders and Zircaloy oxide films: tetragonal phase evolution during $400^{\circ} \mathrm{C}$ autoclave tests', Journal of Nuclear Materials, 1995, 226(1-2), 34-43.

54. H.-J. Beie, A. Mitwalsky, F. Garzarolli, H. Ruhmann, and H.-J. Sell: 'Examinations of the Corrosion Mechanism of Zirconium Alloys', 10th International Symposium on Zirconium in the Nuclear Industry: , Baltimore, MD, $21-24$ June 1993, 1994, ASTM International, 615-643.

55. M. Harada, M. Kimpara, and K. Abe: 'Effect of Alloying Elements on Uniform Corrosion Resistance of Zirconium-Based Alloy in $360^{\circ} \mathrm{C}$ Water and $400^{\circ} \mathrm{C}$ Steam', 9th International Symposium on Zirconium in the Nuclear Industry, Kobe, Japan, 58 November 1990, 1991, ASTM International, 368-390.

56. J. P. Mardon, D. Charquet, and J. Senevat: 'Optimization of PWR Behavior of StressRelieved Zircaloy-4 Cladding Tubes by Improving the Manufacturing and Inspection Process', 10th International Symposium on Zirconium in the Nuclear Industry: , Baltimore, MD, 21-24 June 1993, 1994, ASTM International, 328-347.

57. K. Takeda and H. Anada: 'Mechanism of Corrosion Rate Degradation Due to Tin', 12th International Symposium on Zirconium in the Nuclear Industry, Toronto, Canada, 15-18 June 1998, 2000, ASTM International, 592-608.

58. P. Li, I. W. Chen, and J. E. Penner-Hahn: 'Effect of Dopants on Zirconia Stabilization-An X-ray Absorption Study: II, Tetravalent Dopants', Journal of the American Ceramic Society, 1994, 77(5), 1281-1288.

59. D.-J. Kim, J.-W. Jang, and H.-L. Lee: 'Effect of Tetravalent Dopants on Raman Spectra of Tetragonal Zirconia', Journal of the American Ceramic Society, 1997, 80(6), 1453-1461.

60. B. Cox and J. P. Pemsler: 'Diffusion of oxygen in growing zirconia films', Journal of Nuclear Materials, 1968, 28(1), 73-78.

61. B. Cox and C. Roy, Electrochemistry Technology, 1966, 4, 121.

62. R. A. Ploc: 'Transmission electron microscopy of thin (\&lt;2000 å) thermally formed ZrO2 films', Journal of Nuclear Materials, 1968, 28(1), 48-60.

63. R. A. Ploc: 'A transmission electron diffraction study of $\mathrm{ZrO} 2$ on $\alpha-\mathrm{Zr}$ (0001)', Journal of Nuclear Materials, 1982, 110(1), 59-64. 
64. R. A. Ploc: 'Electron diffraction from ZrO2 on $\alpha \mathrm{Zr}(101 \& a m p ; \# x 0304 ; 0)$ ', Journal of Nuclear Materials, 1983, 115(1), 110-117.

65. R. A. Ploc: 'Electron diffraction analysis of $\mathrm{ZrO2}$ on $\alpha \mathrm{Zr}(112 \& a m p ; \# \times 0304 ; 0)$ ', Journal of Nuclear Materials, 1983, 113(1), 75-80.

66. A. Yilmazbayhan, E. Breval, A. T. Motta, and R. J. Comstock: 'Transmission electron microscopy examination of oxide layers formed on $\mathrm{Zr}$ alloys', Journal of Nuclear Materials, 2006, 349(3), 265-281.

67. B. Cox: ' in 'Advances in Corrosion Science and Technology', (eds. M. G. Fontana, et al.), 173; 1976, New York, Plenum.

68. A. T. Donaldson and H. E. Evans: 'Oxidation-induced Creep in Zircaloy-2, Parts I-III', Central Electricity Generating Board, Berkeley Nuclear LabsUK Reports, RD/T/N4855, 4952 and 4976, Berkeley, UK, 1980.

69. N. Ni, S. Lozano-Perez, M. L. Jenkins, C. English, G. D. W. Smith, J. M. Sykes, and C. R. M. Grovenor: 'Porosity in oxides on zirconium fuel cladding alloys, and its importance in controlling oxidation rates', Scripta Materialia, 2010, 62(8), 564-567.

70. J.-Y. Park, B.-K. Choi, S. J. Yoo, and a. Y. H. Jeong: 'Corrosion and Oxide Properties of HANA alloys', 15th International Symposium on Zirconium in the Nuclear Industry, Sunriver Resort Oregon, USA, 24-28 June 2007, 2009, ASTM International 471-485.

71. P. Bossis, B. Verhaeghe, S. Doriot, D. Gilbon, V. Charbretou, A. Dalmais, J.-P. Mardon, M. Blat, and A. Miquet: 'In PWR Comprehensive Study of High Burn-Up Corrosion and Growth Behavior of M5 and Recrystallized Low-Tin Zircaloy-4', 15th International Symposium on Zirconium in the Nuclear Industry, Sunriver Resort Oregon, USA, 24-28 June 2007, 2009, ASTM International 430-456.

72. H. K. Yueh, R. L. Kesterson, R. J. Comstock, H. H. Shah, D. J. Colburn, M. Dahlback, and L. Hallstadius: 'Improved ZIRLO ${ }^{\mathrm{TM}}$ Cladding Performance through Chemistry and Process Modifications', 14th International Symposium on Zirconium in the Nuclear Industry, Stockholm, Sweden, 13-17 June 2004, 2005, ASTM International, 330-348.

73. Y. Takagawa, S. Ishimoto, Y. Etoh, T. Kubo, K. Ogata, and O. Kubota: 'The Correlation Between Microstructures and in-BWR Corrosion Behavior of Highly Irradiated Zr-based Alloys', 14th International Symposium on Zirconium in the Nuclear Industry, Stockholm, Sweden, 13-17 June 2004, 2005, ASTM International, 386-403.

74. H.-J. Sell, S. Trapp-Pritsching, and F. Garzarolli: 'Effect of Alloying Elements and Impurities on in-BWR Corrosion of Zirconium Alloys', 14th International Symposium on Zirconium in the Nuclear Industry, Stockholm, Sweden, 13-17 June 2004, 2005, ASTM International, 404-417.

75. M. Dahlbäck, M. Limbäck, L. Hallstadius, P. Barberis, G. Bunel, C. Simonot, T. Andersson, P. Askeljung, J. Flygare, B. Lehtinen, and A. R. Massih: 'The Effect of Beta-Quenching in Final Dimension on the Irradiation Growth of Tubes and Channels', 14th International Symposium on Zirconium in the Nuclear Industry, Stockholm, Sweden, 13-17 June 2004, 2005, ASTM International, 276-304.

76. J. Arborelius, M. Dahlbäck, L. Hallstadius, P. Jourdain, T. Andersson, R. Lisdat, M. Hahn, and E. H. Toscano: 'The Effect of Duplex Cladding Outer Component Tin Content on Corrosion, Hydrogen Pick-up, and Hydride Distribution at Very High Burnup', 14th International Symposium on Zirconium in the Nuclear Industry, Stockholm, Sweden, 13-17 June 2004, 2005, ASTM International, 526-546.

77. F. Garzarolli, H. Ruhmann, and L. V. Swam: 'Alternative Zr Alloys with Irradiation Resistant Precipitates for High Burnup BWR Application', 13th International Symposium on Zirconium in the Nuclear Industry, Annecy, France, 10-14 June 2001, 2002, ASTM International, 119-134. 
78. Y. Etoh, S. Shimada, T. Yasuda, T. Ikeda, R. B. Adamson, J.-S. F. Chen, Y. Ishii, and K. Take: 'Development of New Zirconium Alloys for a BWR', 11th International Symposium on Zirconium in the Nuclear Industry, Garmisch-Partenkirchen, Germany, 11-14 Sept. 1995, 1996, ASTM International, 825-849.

79. Young S. Kim, K. S. Rheem, and D. K. Min: 'Phenomenological Study of In-Reactor Corrosion of Zircaloy-4 in Pressurized Water Reactors', 10th International Symposium on Zirconium in the Nuclear Industry: , Baltimore, MD, 21-24 June 1993, 1994, ASTM International, 745-759.

80. F. Garzarolli, R. Schumann, and E. Steinberg: 'Corrosion Optimized Zircaloy for Boiling Water Reactor (BWR) Fuel Elements', 10th International Symposium on Zirconium in the Nuclear Industry: , Baltimore, MD, 21-24 June 1993, 1994, ASTM International, 709-723.

81. A. M. Garde, S. R. Pati, M. A. Krammen, G. P. Smith, and R. K. Endter: 'Corrosion Behavior of Zircaloy-4 Cladding with Varying Tin Content in High-Temperature Pressurized Water Reactors', 10th International Symposium on Zirconium in the Nuclear Industry: , Baltimore, MD, 21-24 June 1993, 1994, ASTM International, 760778. 